\title{
Numerical investigation on diesel combustion and emissions with a standard combustion model and detailed chemistry
}

\begin{abstract}
The aim of this study was to determine possibilities of the soot and $N O_{x}$ emissions reduction from an existing heavyduty compression-ignition (CI) engine based only on in-cylinder techniques. To that end numerical simulations of such processes as a multiphase fuel flow through injector nozzles, a liquid fuel jet breakup and evaporation, combustion and emissions formation were performed in AVL Fire 3D CFD software. The combustion process was calculated with the ECFM-3Z model and with the detailed n-heptane oxidation scheme that consisted of 76 species and 349 reactions. Both approaches of combustion modeling were validated against experimental data from the existing engine working under $75 \%$ and $100 \%$ loads. As for the reduction of the $N O_{x}$ emission an introduction of exhaust gas recirculation (EGR) was investigated. As for the soot concentration reduction such measures as an increased rail pressure, application of a postinjection and an increased injector nozzles conicity were investigated. Finally the ECFM-3Z model with emissions models, as well as the n-heptane mechanism predicted that it is possible to reach specified emissions limits with application of $E G R$, post-injection and increased nozzles conicity.
\end{abstract}

Key words: diesel, n-heptane, ECFM-3Z model, combustion, emissions, soot, $N O_{x}$, EGR, post-injection

\section{Introduction}

The development of the industrial sector became the reason of the emissions growth. According to [1] transport is the source of $13 \%$ of the global greenhouse gas emissions. Apart from $\mathrm{CO}_{2}$, during combustion process in the internal combustion engines $\mathrm{NO}_{x}, \mathrm{CO}$, unburned hydrocarbons (UHC) and particulate matter (mostly soot) are generated. These pollutants are harmful not only for the environment but also for the humans. In order to reduce their level in the atmosphere and impact on people's health emissions standards have been introduced and are updated every couple of years. In the United States emission standards are managed on a national level by the Environmental Protection Agency (EPA) and currently Phase 3A is in force (2010-2016). In European Union current emission standard for passenger cars and light commercial vehicles is Euro 6 defined in a series of directives. As for the marine application engines emission standards are introduced by International Maritime Organization (IMO) which is the United Nations specialized agency with responsibility for the safety and security of shipping and the prevention of marine pollution by ships. The new standards Tier III that will be introduced in 2016 require reduction of $\mathrm{NO}_{\mathrm{x}}$ by $80 \%$ in regard to the current regulations in the Emission Control Areas [2].

Because of the enforced emission standards manufacturers are obligated to continuously decrease emissions from vehicles they produce. The main challenge for modern compression-ignition (CI) engines is to simultaneously reduce soot and $\mathrm{NO}_{x}$ concentrations in exhaust gases while maintaining fuel efficiency. Both after-treatment and incylinder strategies are adopted in practice to reduce these emissions. However, after-treatment systems have issues of cost, packaging and fuel efficiency penalties. Therefore, incylinder combustion control techniques are more favorable when it comes to pollutant emissions reduction in internal combustion engines. The most popular and very effective method for $\mathrm{NO}_{\mathrm{x}}$ reduction is application of exhaust gas recirculation (EGR). Redirecting some of the exhaust gases back into the combustion chamber results into lower temperatures during the combustion process and lower $\mathrm{NO}_{x}$ concentrations. Although EGR application may reduce $\mathrm{NO}_{x}$ emission significantly, it usually results in undesirable soot emission increase due to lowering the oxygen concentration. Thus, together with EGR, additional measures against soot emission need to be taken in order to meet both soot and $\mathrm{NO}_{\mathrm{x}}$ legislation levels in $\mathrm{CI}$ engines.

One of the possibilities of soot reduction in $\mathrm{CI}$ engine is intensification of air-fuel mixing during the combustion process. It can be achieved by increased injection pressure or modified injector nozzles geometry that allow better spray atomization and fuel evaporation. Better mixing results in intensification of the soot oxidation during the combustion process and lower soot concentration overall. Furthermore, the use of close-coupled post-injections is another in-cylinder strategy that has been proved to be effective for soot reduction. Closed-coupled post-injection features a main fuel injection as in conventional CI engines, followed by a relatively small amount of post injected fuel, where the dwell between the end of main-injection and the start of postinjection is short, typically a few crank angle degrees.

Much experimental and numerical work has been conducted to verify the efficacy of post-injection in soot reduction. Reitz et al. in [3-5] analyzed a possibility of simultaneous soot and $\mathrm{NO}_{\mathrm{x}}$ emission reduction with post-injection. With tests and analysis on a single cylinder version of the Caterpillar 3406 heavy duty CI engine, they concluded that the soot reduction is affected by the fueling ratio and the dwell between two or more injection pulses, and there exists an optimum injection scheme for soot emission control. O'Connor and Musculus [6] reviewed a current understanding of Post-Injections influence on soot reduction in CI 
engines and they concluded that Post-Injection strategies can be implemented without a penalty in $\mathrm{NO}_{\mathrm{x}}$ and they usually become more effective in soot reduction at higher rates of EGR. Most recently Yue et al. [7] using KIVA 3D CFD code validated detailed chemical scheme proposed in $[8,9]$ for multi-dimensional engine CFD modeling and emissions prediction in CI engines. Authors confirmed that the mechanism predicts combustion process and soot concentrations under engine operating conditions with Post-Injection with good agreement. They also developed an analysis method, which can quantify and visualize soot formation, soot oxidation, soot from Main-Injection and soot from Post-Injection individually. With this tool it was possible to observe that both soot formation and soot oxidation are enhanced by PostInjection. Soot formation is increased due to larger amount of fuel injected and the soot oxidation is enhanced due to an elevation of temperature, which is more likely to be the reason of net soot reduction by Post-Injection.

The aim of the present study is to verify possibilities of soot and $\mathrm{NO}_{\mathrm{x}}$ emissions reduction in an existing heavyduty $\mathrm{CI}$ engine to the level of Tier III emission standards that will be binding in maritime applications since 2016 . Firstly, four engine cases were modeled using AVL Fire CFD solver, featuring two approaches - combustion simulations with ECFM-3Z model with emissions models and simulations with a detailed chemistry mechanism that was able of $\mathrm{NO}_{\mathrm{x}}$ concentration and soot precursors prediction. These cases, corresponding to four engine operating points with conventional single-pulse injection, were validated against measurements in terms of $\mathrm{NO}_{x}$ concentration, soot concentration, IMEP and pressure trace consistence. Once the model was validated further simulations were conducted including increased rail pressure, increased nozzles conicity and introduction of the Post-Injection. Finally, influence of these measures on emissions was compared. Also differences between results obtained with the models and the mechanism were presented and commented.

\section{Simulation tools}

The AVL Fire code was used in this study to provide the CFD simulations. As for turbulence modeling, the $k-\zeta-f$ model [10] was applied. The spray breakup was predicted by two models - blob injection for primary breakup and WAVE-child for secondary breakup [11]. The combustion process was modeled with use of the ECFM-3Z model with kinetic model for soot and extended Zeldovich model for $\mathrm{NO}_{\mathrm{x}}$ formation $[12,13]$. Furthermore, each considered combustion case was also calculated with detailed chemical scheme for n-heptane/n-butanol fuel blends [9] that consisted of 76 species and 349 reactions. The mechanism included submechanisms for $\mathrm{NO}_{\mathrm{x}}$ formation and for soot prediction through the 4-ring PAH species, pyrene.

In order to reduce the computational time needed for $3 \mathrm{D}$ CFD simulations with detailed chemistry, the multi-zone chemistry solution method was used. This method reduces the total computational resources required for the solution by introduction of a reduced number of zones for chemistry calculation. The computational zones with similar tempera- tures and equivalence ratios are mapped on to this reduced set of zones for which chemistry is solved. After the chemistry calculation, the species concentration and internal energies are mapped back on to the fully-resolved computational grid. Thanks to this approach in investigated cases the chemistry was solved for approximately 8000-14000 zones instead of every computational cell.

\section{Simulation setup}

\subsection{Nozzle flow simulations}

The combustion process taking place in CI engines is strongly dependent on fuel injection and mixture preparation. Proper prediction of such processes as liquid fuel jet breakup, fuel evaporation and mixing is essential for combustion simulations. In order to obtain most realistic conditions for fuel ignition and combustion, for each setup considered in this study simulations of fuel flow through the injector nozzles were conducted. Results of the flow parameters at nozzle orifices exit were written in the nozzle file. Next, these files were used as an input data for spray prediction during the combustion simulations.

In the common-rail direct injection system, the single injector is supplied with the fuel under high pressure from the common fuel accumulator. Liquid fuel is injected into the combustion chamber through multiple injector nozzles. In this study two levels of fuel pressures are considered - basic pressure $p_{\text {in }}=1500$ bar and increased pressure $p_{\text {in }}=1800$ bar. In case of increased pressure, orifice outlet diameter was reduced in order to retain the same fuel mass flow. The injection process is driven by the needle movement. For transient simulations of the injection process the experimental needle lift profiles and fuel pressure profiles are used (Fig. 1).

Because of the construction of the injector a pressure wave is traveling back and forth during the injection process
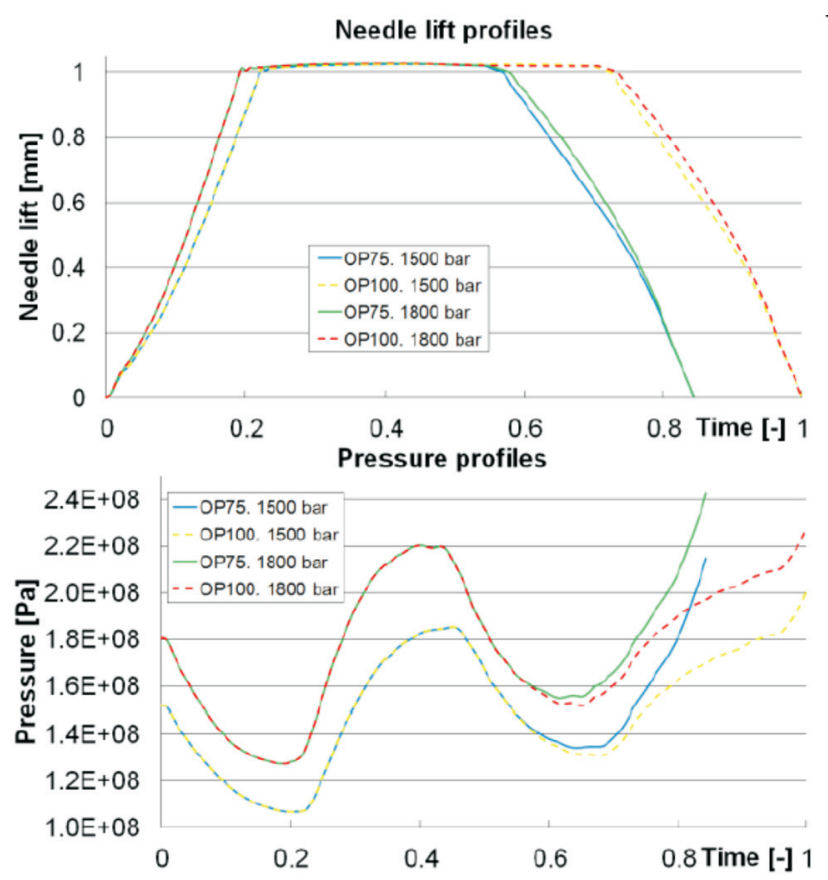

Fig. 1. Needle lift and injection pressure profiles 
resulting in significant pressure fluctuations in the nozzles which could affect post-injection. Thus, in order to apply post-injection, a new injector with compensation volume was designed and nozzle flow simulations for cases with post-injection were calculated with constant pressure inlet boundary condition.

Nozzle flow was calculated for real injector geometry, which involved 12 nozzles arranged in 2 rows (Fig. 2). All nozzles considered in this study have the same orifice inlet rounding $r$ and bore length $\mathrm{L}$, but differ in diameter of the bore and conicity factor. However, for each investigated case the same fuel mass flow is always retained by changing orifice outlet diameter. The nozzle conicity factor $\mathrm{K}$ is defined as:

$$
\mathrm{K}=\frac{\mathrm{D}_{\text {in }}-\mathrm{D}_{\text {out }}}{\mathrm{L}} \times 100
$$

Three different conicity factors $\left(\mathrm{K}_{0}, \mathrm{~K}_{3}, \mathrm{~K}_{6}\right)$ were considered for each nozzle. The conicity factor $\mathrm{K}_{0}$ means that the nozzle has cylindrical shape. A cross-section through one of the nozzles with marked different $\mathrm{K}$-factors is presented in Fig. 2.
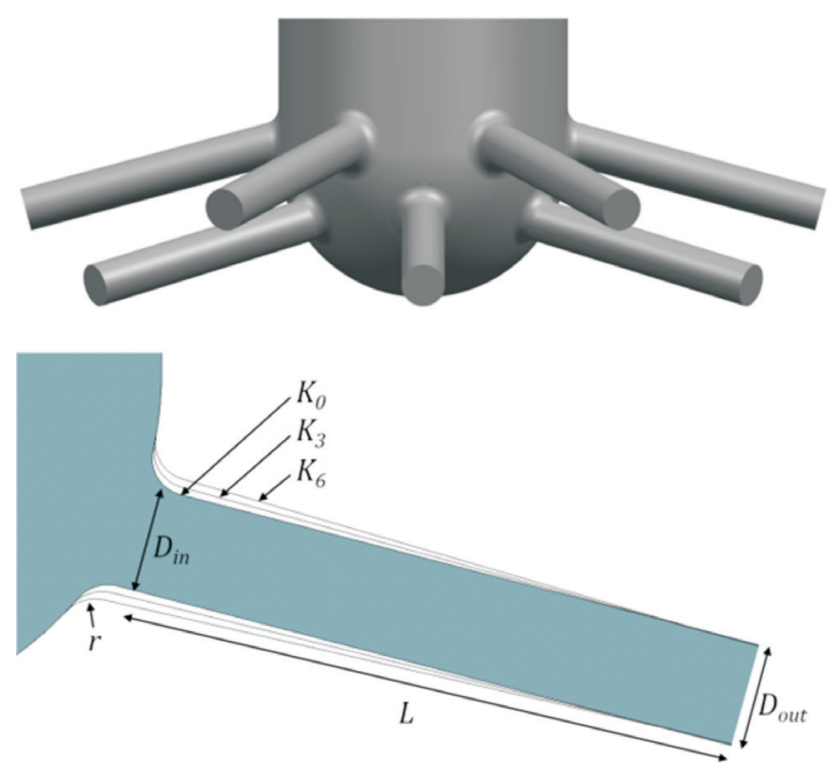

Fig. 2. Considered injector geometry

For the purposes of this study, six meshes for three different $\mathrm{K}$-factors and two different fuel pressures were prepared. Thanks to 12 injector symmetry planes, single mesh covered $1 / 12^{\text {th }}$ of the injector volume including 2 injector nozzles. All meshes were structural, consisting entirely of hexahedral elements and included moving layers responsible for needle movement simulations. At the outlet of the nozzles additional Dummy Volumes were created to ensure more realistic outlet boundary conditions. One of the meshes with applied boundary conditions is presented in Fig. 3.

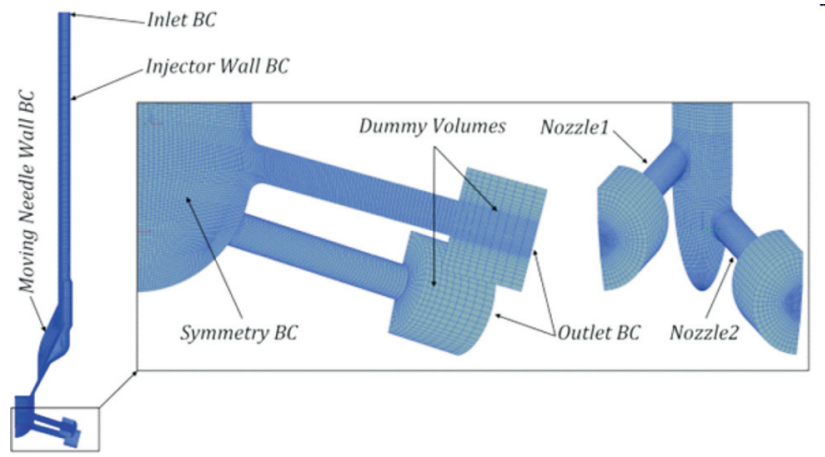

Fig. 3. Mesh for nozzle flow simulations

\subsection{Combustion simulations}

The engine investigated in this study was heavy-duty, 6-cylinder, 4-stroke CI engine for maritime applications. The engine configuration and operating conditions are included in Table 1. Two engine operating points (OP75 - 75\% load and OP100 - 100\% load) and two levels of EGR (0\% and $20 \%$ ) were under investigation.

Two different fuels were considered in this study depending on the simulations approach. Combustion simulations with the ECFM-3Z model were performed for diesel-D1 fuel, which properties represent real light diesel fuel. The most important fuel property in terms of combustion is Lower calorific value (LCV), because it determines total amount of heat released during the cycle and eventually influence the IMEP, fuel consumption and emissions. The LCV of diesel-D1 fuel used for simulations was of $42.34 \mathrm{MJ} / \mathrm{kg}$.

Although the detailed kinetic mechanism used for simulation had the ability of predicting $n$-heptane/n-butanol fuel blends, only n-heptane was investigated in this study as a single component diesel surrogate. Despite similar cetane number, other properties of $n$-heptane differ from real diesel fuel. Especially n-heptane LCV of $44.57 \mathrm{MJ} / \mathrm{kg}$ can influence the combustion process. Because of the higher LCV of n-heptane, the IMEP results obtained from combustion simulations with the mechanism are expected to be up to $5 \%$ higher than values obtained from simulations with the ECFM-3Z model.

Differences in other n-heptane properties can have significant impact on spray development process. Therefore, in combustion simulations that incorporate n-heptane kinetics, physical properties of diesel-D1 fuel are used for spray prediction in order to provide realistic injection, break-up, evaporation and fuel mixing behavior.

In order to perform CFD combustion simulations, such injection parameters as start of injection, injection duration or number of injections during one cycle need to be defined. In this work two injection strategies were considered - maininjection-only (MIO), during which fuel was injected once per cycle, and multiple injection divided into main-injection and post-injection. Injection timings and durations are given in Table 2. 
Table 1. Investigated engine configuration

\begin{tabular}{|l|c|}
\hline Engine type & 6-cylinder, 4-stroke CI \\
\hline Bore & $320 \mathrm{~mm}$ \\
\hline Stroke & $480 \mathrm{~mm}$ \\
\hline Number of nozzle holes & 12 \\
\hline Engine speed & $600 \mathrm{rpm}$ \\
\hline Considered loads & $75 \% / 100 \%$ \\
\hline Considered EGR mass & $0 \% / 20 \%$ \\
\hline
\end{tabular}

Table 2. Considered injection timings

\begin{tabular}{|l|c|}
\hline \multicolumn{2}{|c|}{ Injection timings for OP75 } \\
\hline Start of injection & $0{ }^{\circ} \mathrm{CA}(\mathrm{TDC})$ \\
\hline $\begin{array}{l}\text { Main-injection-only duration }(0 \% / 20 \% \\
\text { EGR) }\end{array}$ & $20.7 / 22^{\circ} \mathrm{CA}$ \\
\hline $\begin{array}{l}\text { Main-injection duration before post-injec- } \\
\text { tion }(20 \% \text { EGR) }\end{array}$ & $20.5^{\circ} \mathrm{CA}$ \\
\hline Dwell between main and post & $3 / 7.5 / 12^{\circ} \mathrm{CA}$ \\
\hline Post-Injection duration (20\% EGR) & $4{ }^{\circ} \mathrm{CA}$ \\
\hline & $-2.5{ }^{\circ} \mathrm{CA}$ \\
\hline Start of injection timings for OP100 \\
\hline $\begin{array}{l}\text { Main-injection_only duration }(0 \% / 20 \% \\
\text { EGR) }\end{array}$ & $24.5 / 25.6{ }^{\circ} \mathrm{CA}$ \\
\hline $\begin{array}{l}\text { Main-injection duration before post-injec- } \\
\text { tion (20\% EGR) }\end{array}$ & $23.8^{\circ} \mathrm{CA}$ \\
\hline Dwell between main and post & $3 / 7.5 / 12^{\circ} \mathrm{CA}$ \\
\hline Post-injection duration (20\% EGR) & $4.2{ }^{\circ} \mathrm{CA}$ \\
\hline
\end{tabular}

For main-injection-only combustion simulations with detailed chemistry injection timings and injected fuel mass were the same as in the experiment. As for simulations with the ECFM-3Z model Start of injection in all cases needed to be shifted $1{ }^{\circ} \mathrm{CA}$ earlier in order to match the measured in-cylinder peak firing pressure (PFP) for $\mathrm{K}_{0}$ nozzle conicity and 1500 bar rail pressure. For $\mathrm{K}_{3}$ and $\mathrm{K}_{6}$ nozzle conicity, as well as for 1800 bar rail pressure, injection timing and injected fuel mass did not change (due to reduced nozzles diameter). In cases with post-injection, start of injection and the fuel mass injected during whole cycle were the same as in corresponding main-injection-only cases. However, the main-injection duration was reduced and resulting difference in fuel mass was injected during the post-injection. Only one post-injection fuel amount, defined as $\mathrm{m}_{\text {post }} / \mathrm{m}_{\text {main }}=0.09$, was considered in this study. For each case with post-injection, three different dwells between main and post were considered $-3{ }^{\circ} \mathrm{CA}, 7.5^{\circ} \mathrm{CA}$ and $12{ }^{\circ} \mathrm{CA}$. The injection rates for combustion simulations are presented in Fig. 4 and relate to $\mathrm{K}_{0}$ nozzle conicity and 1500 bar rail pressure. Injection rates for other nozzles and rail pressure were similar due to adjustment of nozzles diameter.

In order to provide most realistic diesel ignition condition, nozzle files obtained in nozzle flow simulations were used as an input data for spray prediction. Furthermore, specific spray properties, such as liquid penetration length, spray angle and spray shape needed to be adjusted to match real spray properties. Parameters adjustment for these properties was not considered in this work, due to lack of spray experimental data. Instead, primary and secondary breakup parameters adjusted for similar nozzles and conditions were taken from [14] and were used in this study for spray prediction.

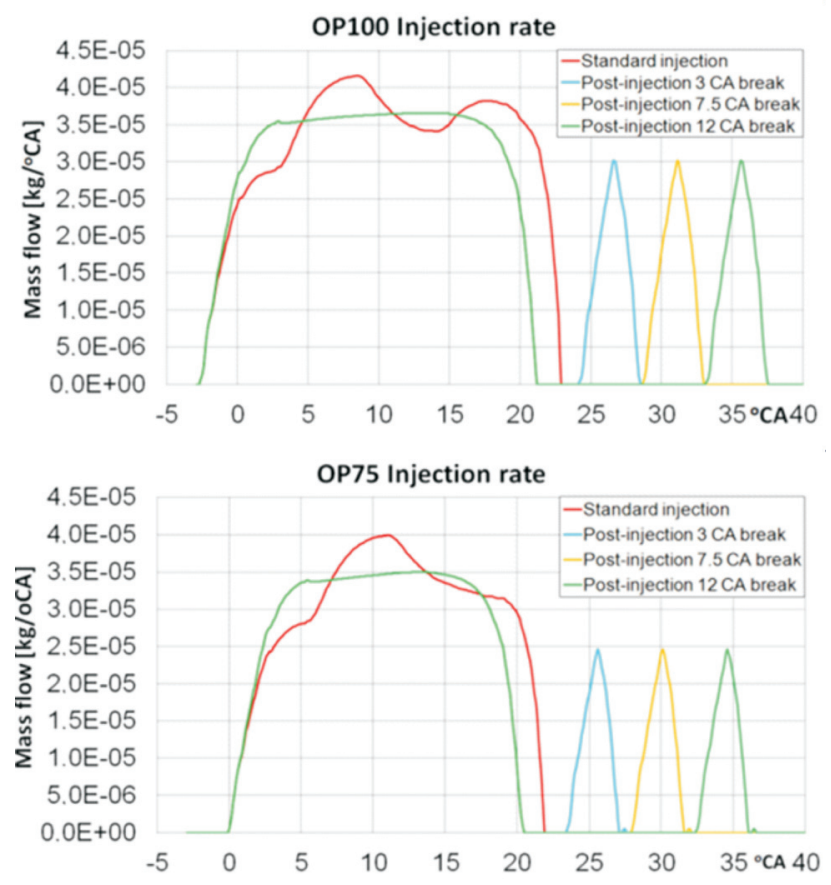

Fig. 4. Considered injection rates

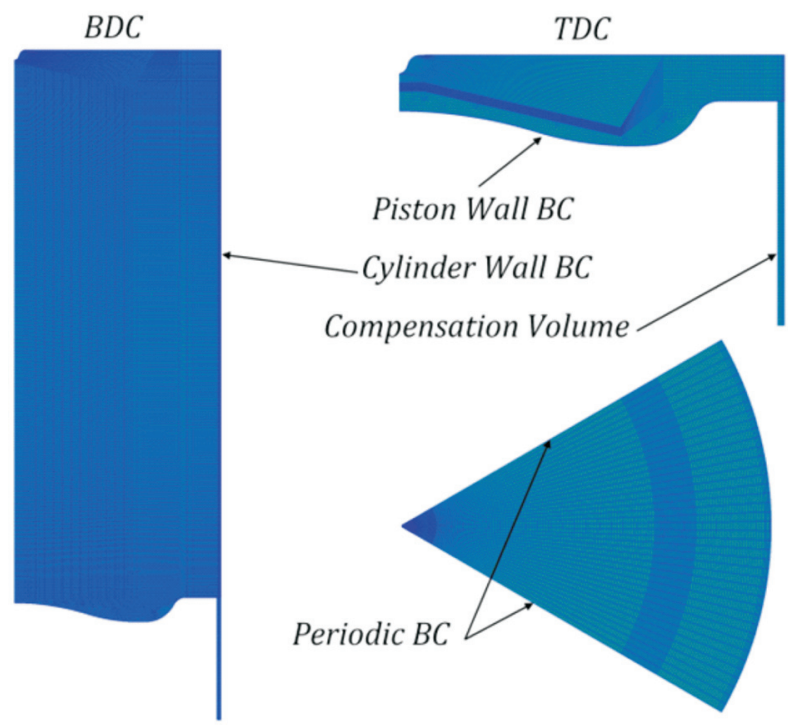

Fig. 5. Numerical mesh with boundary conditions

Combustion simulations covered spray prediction from two nozzles (upper and lower). Structural moving mesh was created for $1 / 6^{\text {th }}$ of the cylinder volume. Intake and exhaust valves were not considered. Instead, a compensation volume was included in the mesh. The number of mesh elements changed during simulations from 426072 cells at top dead center (TDC) to 2092312 cells at bottom dead center (BDC). Numerical mesh with applied boundary conditions at these two positions is presented in Fig. 5. 


\section{Results}

\subsection{Model validation}

The numerical model needed to be validated against experimental data, in order to recognize that results obtained with simulations were trustworthy. Therefore, such results as IMEP, pressure trace, soot emission and $\mathrm{NO}_{\mathrm{x}}$ emission for $100 \%$ and $75 \%$ loads with $0 \%$ and $20 \%$ of EGR were validated against measurements for MIO cases with $\mathrm{K}_{0}$ nozzle and 1500 bar rail pressure. In addition, ignition delays
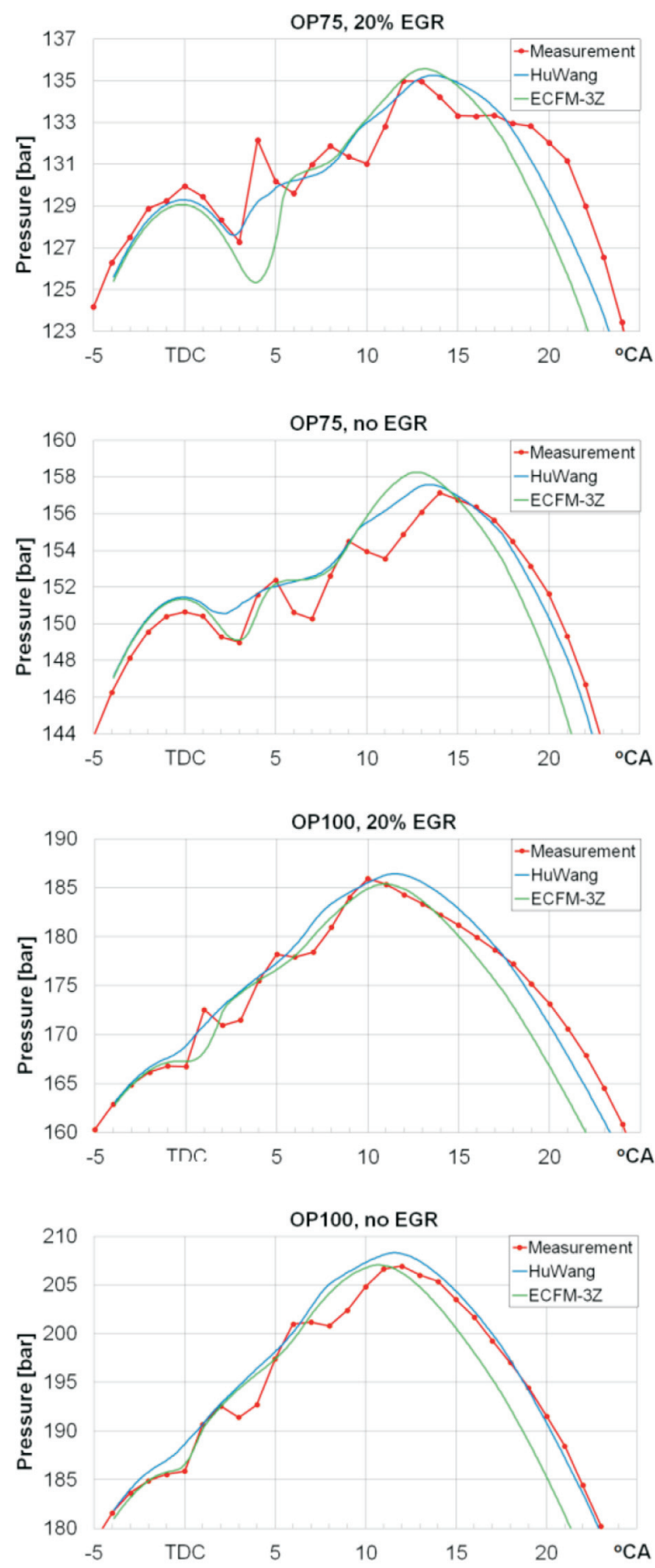

Fig. 6. Pressure trace validation predicted by the model and the mechanism were compared to real ignition delays estimated based on in-cylinder pressure measurement. For soot and $\mathrm{NO}_{x}$ emissions also limits that need to be achieved were defined.

For all considered cases ignition and peak pressure was matched with measurement reasonably well. However, as mentioned before, injection timings in simulations with the ECFM-3Z model needed to be switched $1{ }^{\circ} \mathrm{CA}$ earlier. More differences between the measurement, the ECFM-3Z model and the Wang mechanism can be observed in ignition delay. The definition of the ignition delay is the time lag between the start of injection to start of the combustion. The start of the combustion is taken as the angle value at which heat release rate (HRR) changes from negative to positive [15]. Based on that description, estimated ignition delay times predicted by the kinetic mechanism for n-heptane and by the ECFM-3Z model for diesel-D1 fuel are given in Table 3.

Table 3. Calculated ignition delays

\begin{tabular}{|l|c|c|}
\hline Case & OP75 & OP100 \\
\hline ECFM-3Z 0\% EGR & $2.6^{\circ} \mathrm{CA}$ & $2.4^{\circ} \mathrm{CA}$ \\
\hline ECFM-3Z 20\% EGR & $3.6^{\circ} \mathrm{CA}$ & $3.1^{\circ} \mathrm{CA}$ \\
\hline Wang 0\% EGR & $1.0^{\circ} \mathrm{CA}$ & $0.9^{\circ} \mathrm{CA}$ \\
\hline Wang $20 \%$ EGR & $1.2{ }^{\circ} \mathrm{CA}$ & $1.0^{\circ} \mathrm{CA}$ \\
\hline
\end{tabular}

It is clearly visible that the ECFM- $3 \mathrm{Z}$ model predicts longer ignition delay times for diesel-D1 fuel than the Wang mechanism for $\mathrm{n}$-heptane. Based on pressure trace results and knowing that the injection timings in cases calculated with the model were switched $1{ }^{\circ} \mathrm{CA}$ early, real ignition delay times under investigated conditions can be estimated to be somewhere between the ones predicted by the model and by the mechanism. However, these estimations accuracy is only $1{ }^{\circ} \mathrm{CA}$ due to low pressure measurement resolution.

After the peak pressure is reached differences in its drop are observed in all cases. The in-cylinder pressure drops the fastest in simulations with the ECFM-3Z model. The Wang mechanism predicts the pressure to be closer to the measured value during the power stroke, after the injection. The ECFM-3Z model predicts lower HRR at this stage of combustion and less heat released overall. Since injected fuel mass is the same in cases calculated with the model and the mechanism, this difference can be explained by different lower calorific values of the diesel-D1 fuel and n-heptane. However, the difference up to $5 \%$ was expected in IMEP in favor of the Wang mechanism, while simulations results show that the mechanism predicts $8-9 \%$ higher IMEP than the ECFM-3Z model. In Figure 7 measured IMEP values are compared to predicted ones, showing that both the mechanism and the model underestimated IMEP in all considered cases. Although the Wang kinetic scheme for n-heptane oxidation underestimated the power output and ignition delay times, it was superior to the ECFM-3Z model in combustion simulations for investigated $\mathrm{CI}$ engine operating conditions.

In order to determine the possibilities of emissions reduction based on 3D CFD simulations, reference cases 
needed to be validated against experimental data of emissions concentration. In Figure 8 measured and calculated soot and $\mathrm{NO}_{\mathrm{x}}$ emission concentrations for $\mathrm{MIO}, \mathrm{K}_{0}$ nozzle conicity and 1500 bar rail pressure reference cases are compared. Results of soot and $\mathrm{NO}_{\mathrm{x}}$ mass fractions that were calculated needed to be converted to filter smoke number (FSN) for soot and $\mathrm{g} / \mathrm{kW} \cdot \mathrm{h}$ for $\mathrm{NO}_{\mathrm{x}}$. These conversion takes into account total charge mass and power output. Only after conversion calculated results could be compared against measurements. Emissions targets are 0.5 FSN for soot (which is an equivalent of visible smoke) and 2.5 $\mathrm{g} / \mathrm{kW} \cdot \mathrm{h}$ for $\mathrm{NO}_{\mathrm{x}}$.

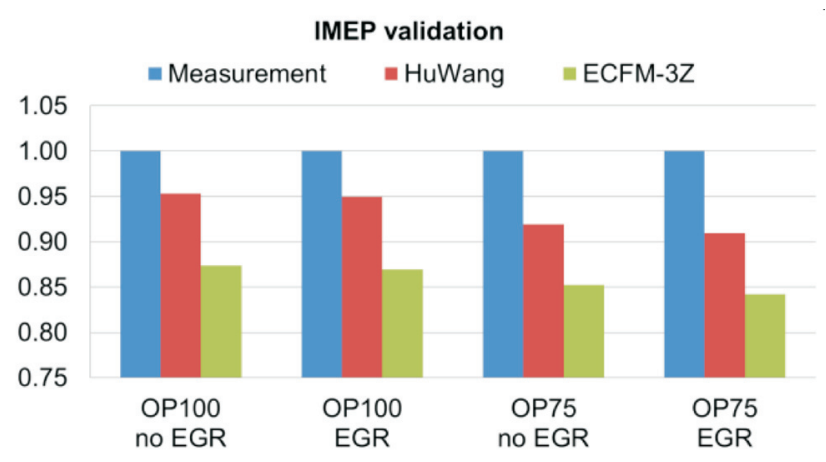

Fig. 7. Results of IMEP for MIO, $\mathrm{K}_{0}$ nozzle conicity and 1500 bar rail pressure normalized in regard to measurements
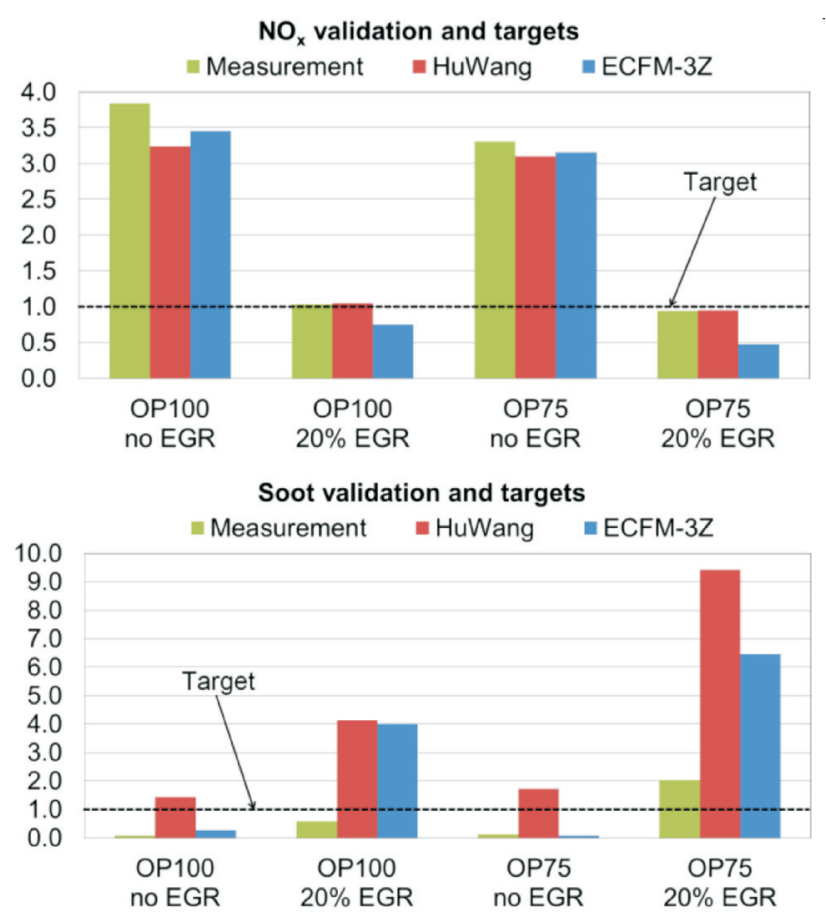

Fig. 8. Soot and $\mathrm{NO}_{\mathrm{x}}$ emissions validation for $\mathrm{MIO}, \mathrm{K}_{0}$ nozzle conicity and 1500 bar rail pressure normalized in regard to the target levels

For $\mathrm{NO}_{\mathrm{x}}$ emission it is observed that both extended Zeldovich model and the Wang mechanism predicted measured values with reasonable agreement for cases without EGR. The measurement is slightly underestimated and results obtained with the model are closer to reality. In cases with
$20 \%$ of EGR the model underestimated the $\mathrm{NO}_{\mathrm{x}}$ emission even more, especially for OP75 (by about 50\%). On the other hand, detailed mechanism predicted the $\mathrm{NO}_{x}$ emission in cases with $20 \%$ of EGR better, matching the measurement for both operating points. As for the targets, it is evident that they can be met only with application of EGR. For OP75 operating point, the level of $20 \%$ EGR was enough to meet $\mathrm{NO}_{x}$ emission targets, while for OP100 operating point with the same level of EGR 5\% reduction in $\mathrm{NO}_{\mathrm{x}}$ emission is still required.

In case of soot emission, results predicted with the ECFM$3 Z$ and Kinetic soot models matched the measurement for cases without EGR, while for $20 \%$ of EGR calculated soot concentrations were overestimated over four times for OP100 operating point and over six times for OP75 operating point. The Wang mechanism overestimated soot concentration even more, especially for cases without EGR, where practically no soot should have been produced according to the measurement and the ECFM-3Z model. The soot emission target is met for both operating points without EGR and for OP100 operating point with $20 \%$ of EGR applied according to measurements. For OP75 operating point with $20 \%$ of EGR, the soot concentration does not meet the target and requires reduction by about $50 \%$. As a conclusion, the $\mathrm{NO}_{x}$ emission is predicted better by the Wang detailed mechanism (matching the measurement for cases with EGR), while the soot emission is predicted better by the kinetic soot model (matching the measurement for cases without EGR). The application of $20 \%$ of EGR resulted in $\mathrm{NO}_{\mathrm{x}}$ concentration reduction to the target level and significant increase in soot concentration. Higher net-soot emission in EGR cases is caused by increased soot production during the combustion process and worse soot oxidation, due to lower level of the oxygen, lower pressures and lower temperatures. Therefore, soot reduction possibilities for cases with $20 \%$ of EGR are also investigated in this study, in order to meet both $\mathrm{NO}_{\mathrm{x}}$ and soot emission targets.

\subsection{Main-injection-only results}

Once numerical model was validated possibilities of emissions reduction could be investigated. In previous subsection it was clearly visible that when it comes to emissions concentration with applied EGR neither models, nor detailed chemistry delivered results that were in agreement with measurements, especially in case of soot. However, knowing required emissions reduction level (from measurements and target limits), it was possible to perform further numerical investigations and compare obtained results with reference cases that were validated. Such approach could give answer of what level of emissions reduction could be expected in regard to reference cases.

In this subsection increased rail pressure (1800 bar) and increased nozzles $\mathrm{K}$-factor $\left(\mathrm{K}_{3}\right.$ and $\left.\mathrm{K}_{6}\right)$ are analyzed as possible measures for soot reduction. Since typical soot- $\mathrm{NO}_{\mathrm{x}}$ trade-off was expected, the influence of undertaken measures on $\mathrm{NO}_{\mathrm{x}}$ concentration was also investigated. Results of IMEP, soot emission and $\mathrm{NO}_{\mathrm{x}}$ emission for MIO cases are presented. All results were normalized in regard to cor- 
responding validated cases $\left(\mathrm{MIO}, \mathrm{K}_{0}\right.$ nozzle conicity and 1500 bar rail pressure). It made results comparable between different $\mathrm{K}$-factors and rail pressures, but not between the ECFM-3Z model and the Wang mechanism.

Firstly, IMEP results should be compared (Fig. 9). For both operating points application of higher fuel pressure and higher nozzles conicity resulted in IMEP increase (also in power output increase) up to $4 \%$ for OP75 operating point with $\mathrm{K}_{6}$ nozzle and 1800 bar rail pressure. It was probably caused by better fuel atomization and mixing, leading to better burning and higher in-cylinder pressures and temperatures. The relative IMEP changes predicted by the ECFM-3Z model and the Wang mechanism are on similar level. Thanks to higher IMEP for the same fuel mass injected, also engine efficiency was increased. Differences in IMEP are important to mention, because emissions concentrations are expressed in terms of power output. Therefore, changes in engine power and efficiency are reflected in $\mathrm{NO}_{x}$ and soot final concentrations.

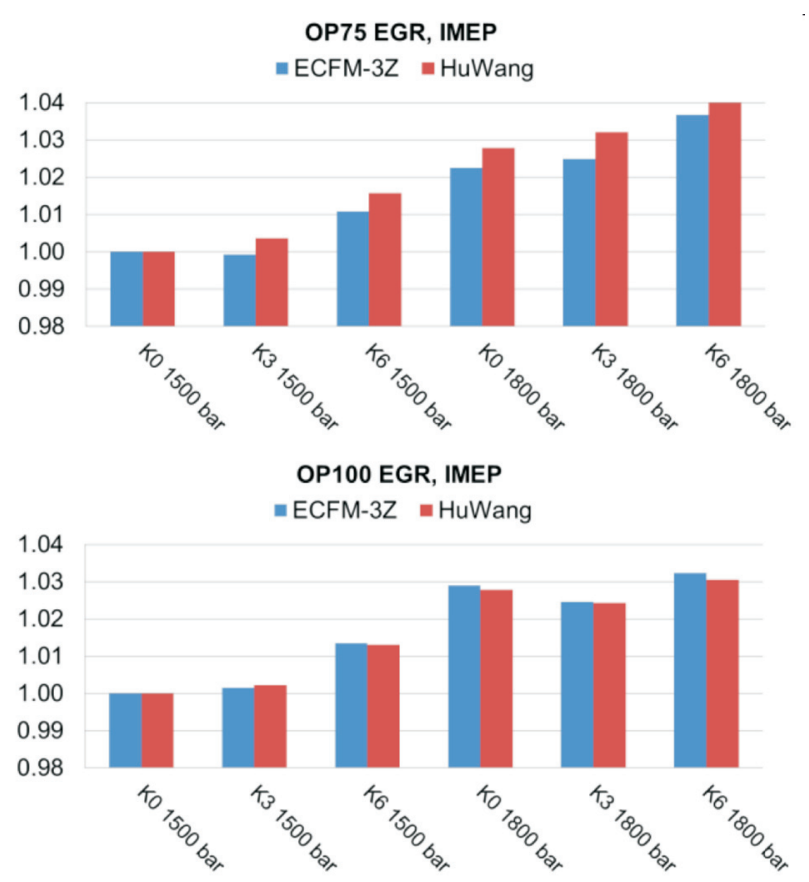

Fig. 9. Normalized IMEP for MIO cases

In Figures 10-13 temperatures and $\mathrm{NO}_{\mathrm{x}}$ formation at cross-section of the upper nozzle during combustion are visualized for OP100 operating point with $20 \%$ of EGR. Results at $738^{\circ} \mathrm{CA}$ are compared between $\mathrm{K}_{0} 1500$ bar and $\mathrm{K}_{6} 1800$ bar MIO cases, for which the biggest differences are expected to be observed. The $\mathrm{NO}_{\mathrm{x}}$ is formed in regions of the highest temperatures (above $2200 \mathrm{~K}$ ), according to the model. Comparing two presented cases it is visible that for $\mathrm{K}_{6}$ nozzle and 1800 bar rail pressure areas of temperatures higher than $2200 \mathrm{~K}$ are bigger which leads to bigger areas of $\mathrm{NO}_{\mathrm{x}}$ formation. The mechanism predicts higher maximum temperatures than the ECFM-3Z model. This difference reaches $200 \mathrm{~K}$ and should have influence on emission results. In case of the Wang mechanism only NO formation is shown (not including $\mathrm{NO}_{2}$ ). However, it should be adequate for comparison, since $\mathrm{NO}$ concentration is $80 \%$ of all $\mathrm{NO}_{\mathrm{x}}$ emission predicted by the mechanism. The $\mathrm{NO}_{\mathrm{x}}$ formation

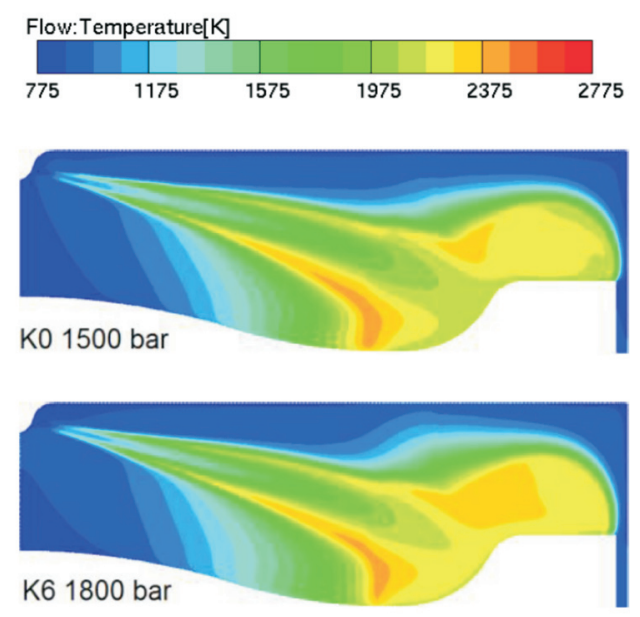

Fig. 10. 3D results of temperature predicted by the ECFM-3Z with extended Zeldovich model for OP $100 \mathrm{MIO}$ at $738^{\circ} \mathrm{CA}$
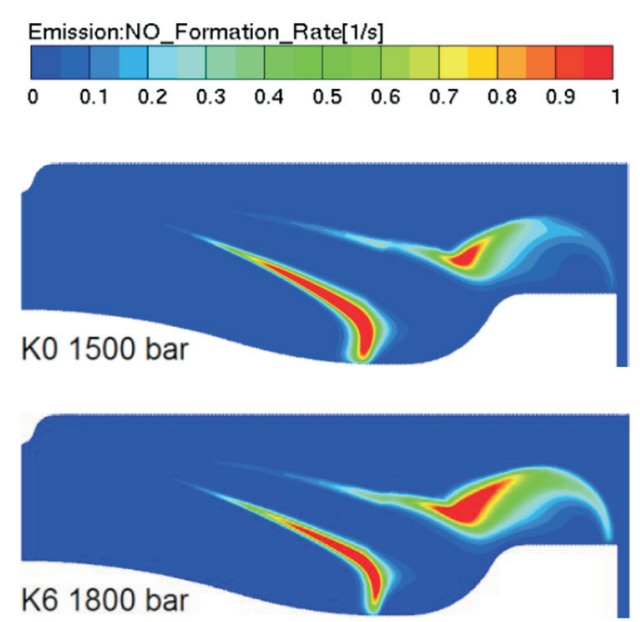

Fig. 11. 3D results of $\mathrm{NO}_{\mathrm{x}}$ formation predicted by the ECFM-3Z model with extended Zeldovich model for OP100 $\mathrm{MIO}$ at $738^{\circ} \mathrm{CA}$
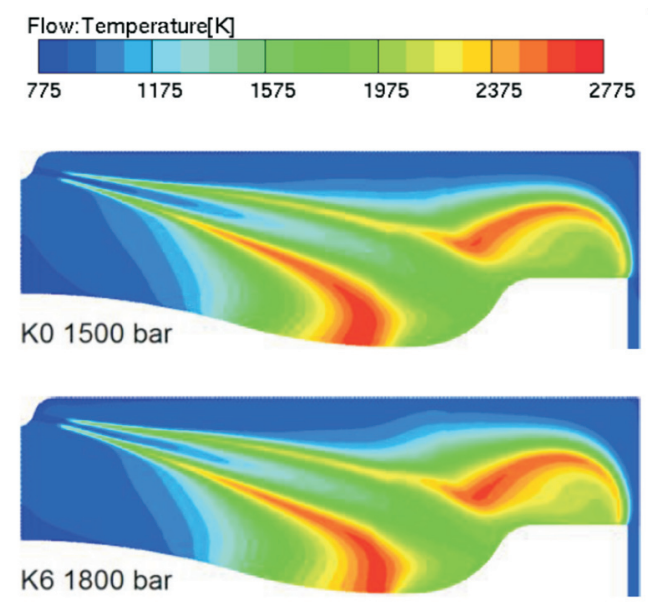

Fig. 12. 3D results of temperature predicted by the Wang mechanism for OP100 MIO at $738^{\circ} \mathrm{CA}$ 

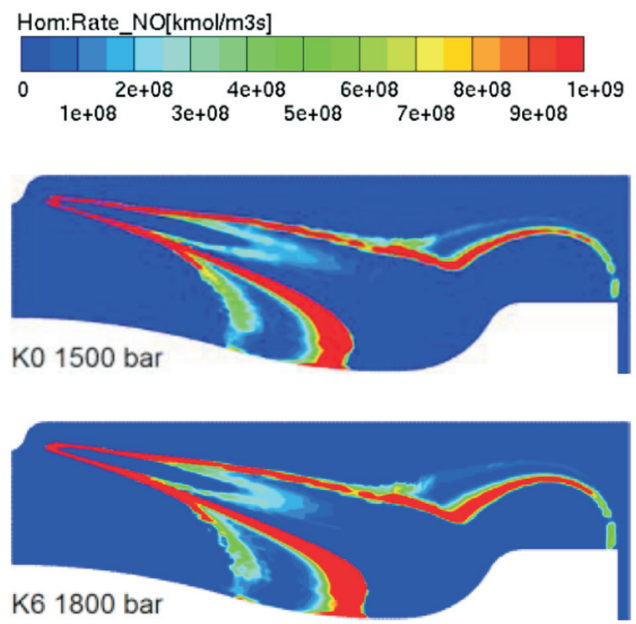

Fig. 13. 3D results of $\mathrm{NO}^{\mathrm{x}}$ formation predicted by the Wang mechanism for $\mathrm{OP} 100 \mathrm{MIO}$ at $738^{\circ} \mathrm{CA}$
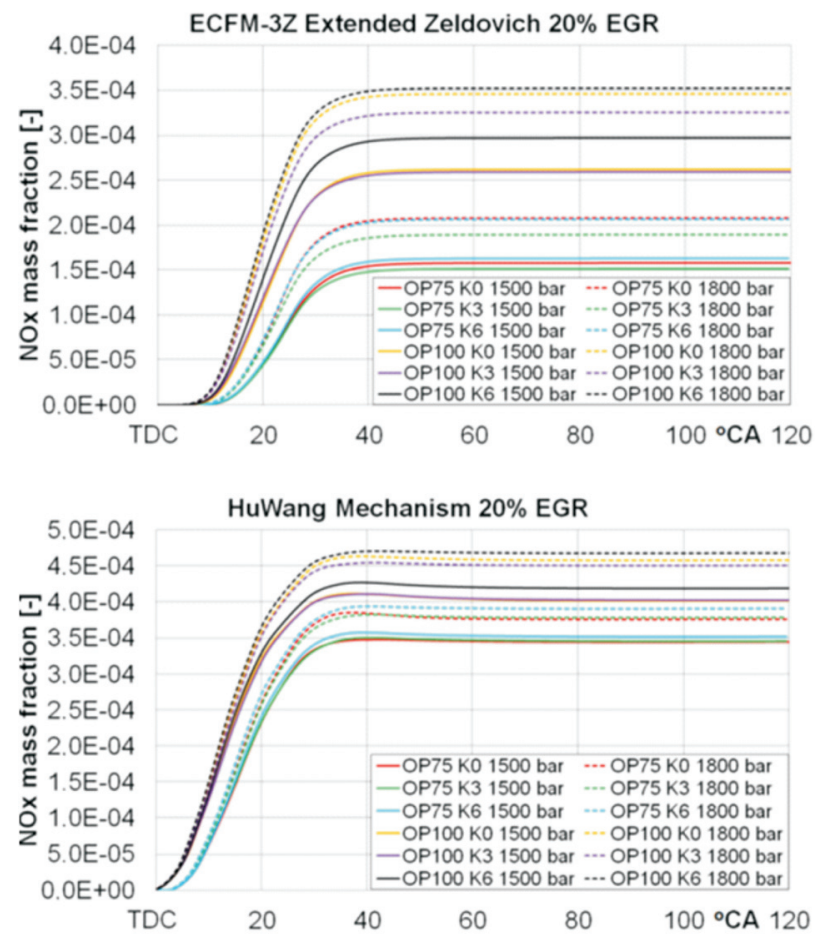

Fig. 14. $\mathrm{NO}_{\mathrm{x}}$ formation $2 \mathrm{D}$ results for MIO cases with $20 \%$ of EGR applied

areas predicted by the mechanism are also different than the ones predicted by the model - $\mathrm{NO}_{\mathrm{x}}$ is formed not only in the areas of the highest temperatures, but also at the flame front where temperatures are lower, but more nitrogen and oxygen is available.

When $2 \mathrm{D}$ results of $\mathrm{NO}_{\mathrm{x}}$ formation are compared (Fig. 14) it can be stated that higher $\mathrm{NO}_{\mathrm{x}}$ emission is predicted for higher rail pressure both by extended Zeldovich model and the Wang mechanism. On the other hand, influence of nozzle $\mathrm{K}$-factor on emissions is not clear. Furthermore, for OP100 engine operating point $\mathrm{NO}_{\mathrm{x}}$ formation starts earlier due to early injection. It can be observed that the Wang mechanism always predicted higher $\mathrm{NO}_{\mathrm{x}}$ concentration than the extended Zeldovich model, as expected based on temperature results.

Soot concentration results are firstly compared based on $3 \mathrm{D}$ results of equivalence ratio and soot formation for OP100 operating point with $20 \%$ of EGR at $738{ }^{\circ} \mathrm{CA}$ (Fig. 15-17). Again, $\mathrm{K}_{0} 1500$ bar and $\mathrm{K}_{6} 1800$ bar MIO cases were chosen for comparison, because the biggest differences between them are expected. Nonetheless, differences between results calculated with the ECFM-3Z model are minor. It can be observed that the area of highest soot formation corresponds to the equivalence ratios of $\varphi>2$. The negative values of the formation reflect the soot oxidation process, which takes place at the perimeters of reacting spray, where more oxygen is available and fuel is better mixed with the air. Soot formation rate predicted by the Wang mechanism shows slightly different behavior. Results of equivalence ratio were not available in this case and only soot precursor (pyrene) formation results are presented. Its main formation area is bigger and located further away from the nozzle than the soot formation predicted by the model. Also more
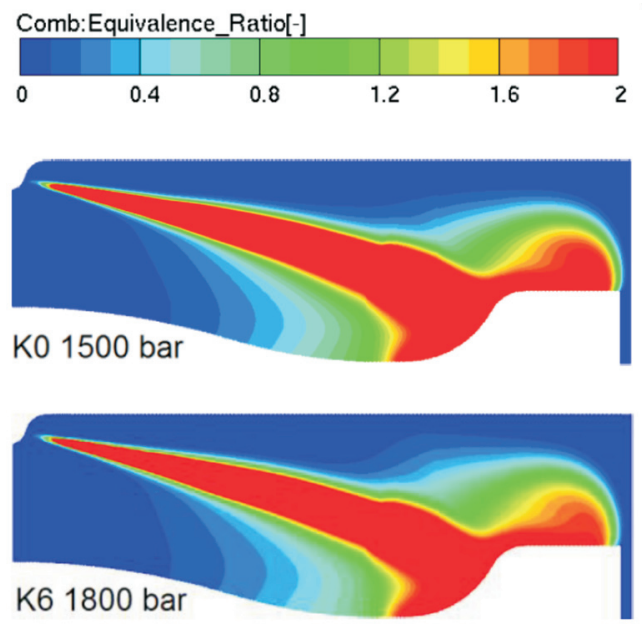

Fig. 15. 3D results of equivalence ratio predicted by the ECFM-3Z model for $\mathrm{MIO}$ at $738^{\circ} \mathrm{CA}$
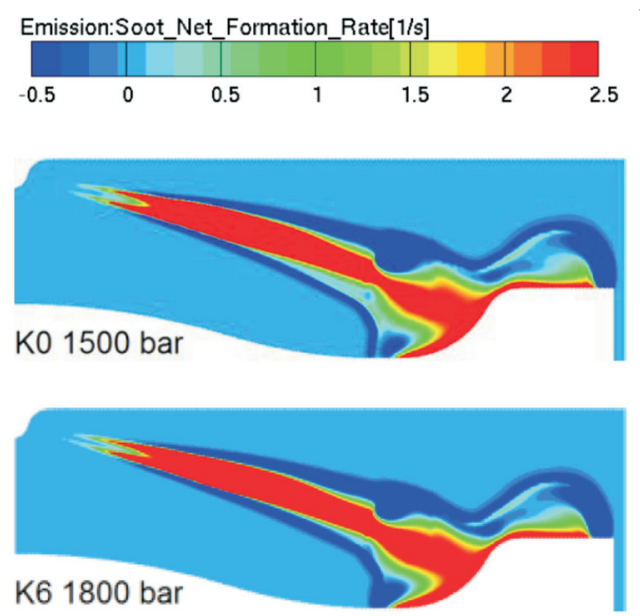

Fig. 16. 3D results of soot formation predicted by kinetic soot model for $\mathrm{MIO}$ at $738^{\circ} \mathrm{CA}$ 
Hom:Rate $\mathrm{A} 4[\mathrm{kmol} / \mathrm{m} 3 \mathrm{~s}]$
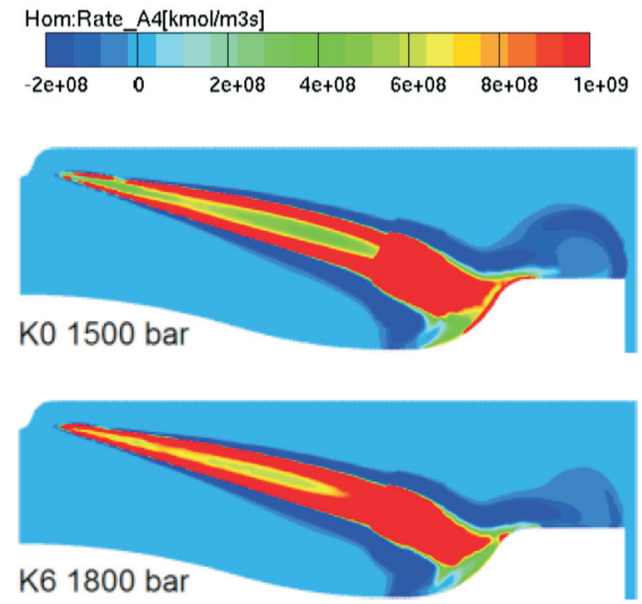

Fig. 17. 3D results of soot precursor (pyrene) formation predicted by the Wang mechanism for $\mathrm{MIO}$ at $738^{\circ} \mathrm{CA}$

clear differences between two compared cases are visible. Smaller soot formation and bigger oxidation areas are observed for $\mathrm{K}_{6}$ nozzle and 1800 bar rail pressure in regard to the reference case.

In Figure 18 2D results of soot formation during combustion are presented. In case of the ECFM-3Z model for all considered cases similar soot formation intensity is observed during the injection. Also similar level of maximum concentration is reached at the end of fuel injection for both operating points, rail pressures and all nozzles $\mathrm{K}$-factors. The differences are observed after the end of injection, where soot oxidation rate differ between cases. The oxidation takes place till the exhaust valve opening at
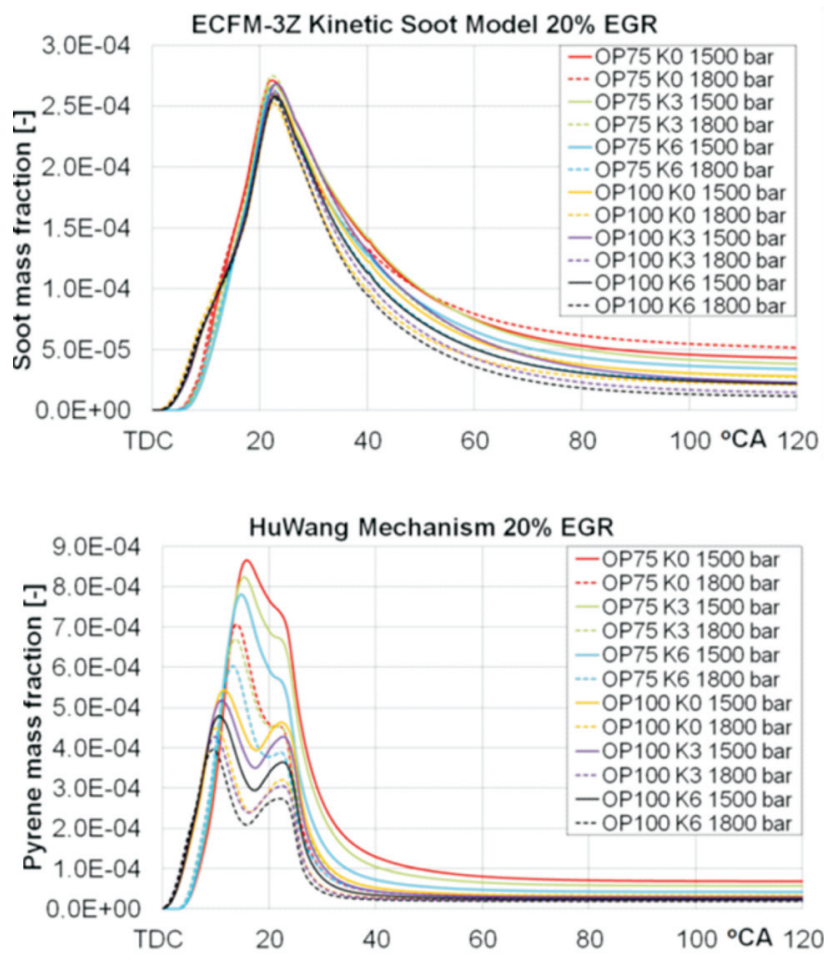

Fig. 18. Soot formation 2D results for MIO cases with 20\% of EGR applied $120^{\circ} \mathrm{CA}$. In general soot reduction rate is higher for higher rail pressure and nozzle conicity resulting in lower emissions at the end. Only for OP75 operating point, $\mathrm{K}_{0}$ nozzle and 1800 bar rail pressure soot reduction rate is visibly lower and in this case final soot emission is the highest. The reason of this behavior might be related to the fact that it was the only case for which significant amount of vapor phase was present at the outlet of the nozzle orifice during the injection.

Soot formation and oxidation behavior predicted by the Wang mechanism is visibly different. The maximum soot concentration is reached earlier and is higher for higher rail pressure and nozzle K-factors. Also fuel mass flow fluctuations are reflected in soot concentration results as two local maxima observed especially for OP100 operating point cases. Unlike in the ECFM-3Z model simulations, soot oxidation predicted by the Wang mechanism takes the dominant role before the end of injection and last shorter. The oxidation is finished between $60{ }^{\circ} \mathrm{CA}$ and $70{ }^{\circ} \mathrm{CA}$ and soot mass fraction does not change after this point. The differences between final soot concentrations calculated with the Wang mechanism are much smaller than the differences between results calculated with the ECFM-3Z model.

Since both $\mathrm{NO}_{\mathrm{x}}$ (by 5\% for OP100 operating point) and soot (by 50\% for OP75 operating point) emission reduction is required and trade-off between these two pollutants is expected, all results are presented in Fig. 19 in order to decide which direction should be followed. Presented results were normalized in regard to $\mathrm{K}_{0}$ nozzle conicity and 1500 bar rail pressure reference cases separately for OP75 operating point, OP100 operating point, the ECFM$3 \mathrm{Z}$ model and the Wang mechanism. Before normalizing, calculated mass fraction concentrations were converted to $\mathrm{g} / \mathrm{kW} \cdot \mathrm{h}$ for $\mathrm{NO}_{\mathrm{x}}$ emission and $\mathrm{mg} / \mathrm{kW} \cdot \mathrm{h}$ for soot emission in order to take into account IMEP (power output) differences between cases. Also targets that need to be met are marked on the charts.

From presented results it can be concluded that increased rail pressure resulted in rise of the $\mathrm{NO}_{\mathrm{x}}$ emission by about $20 \%$ according to the ECFM-3Z model and by $5-10 \%$ according to the Wang mechanism. The soot emission is in general reduced with application of the higher rail pressure, but the level of reduction is different for individual cases. Only for OP75 operating point and $\mathrm{K}_{0}$ nozzle conicity soot concentration was increased for 1800 bar rail pressure. Although higher rail pressure resulted in soot reduction, its application also led to increase in $\mathrm{NO}_{\mathrm{x}}$ concentration. As for different nozzle $\mathrm{K}$-factors it was observed that in general both the ECFM-3Z model and the Wang mechanism predict soot emission to drop with $\mathrm{K}$-factor rise. In case of the $\mathrm{NO}_{\mathrm{x}}$ emission the extended Zeldovich model predicted the lowest concentrations for $\mathrm{K}_{3}$ nozzle conicity and the highest concentrations for $\mathrm{K}_{6}$ nozzle conicity, while $\mathrm{NO}_{\mathrm{x}}$ results concentration calculated with the Wang mechanism were higher for higher nozzle K-factor with only one exception in investigated cases and very small differences between all K-factors for OP75 operating point and 1500 bar rail pressure. 

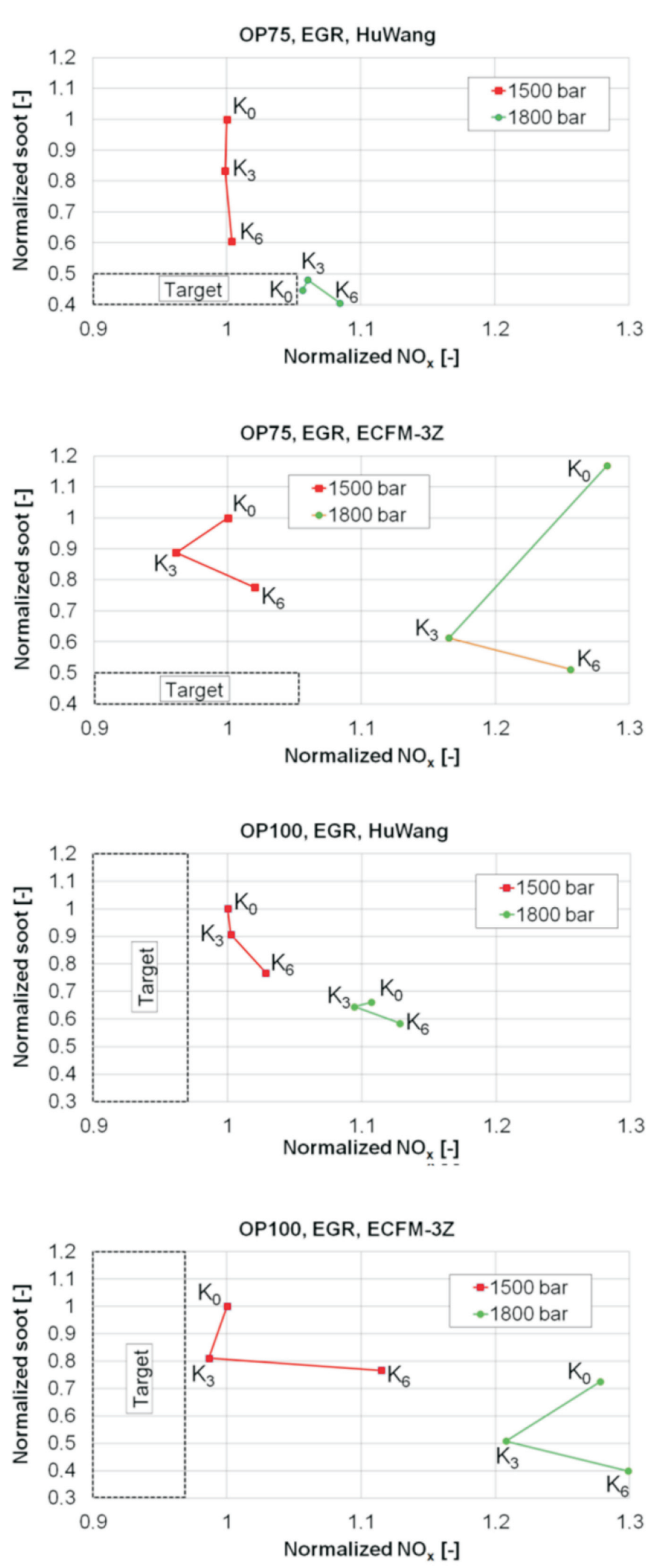

Fig. 19. Soot-NO trade-off for MIO cases

Although it was possible to reduce soot concentration for OP75 operating point by over $20 \%$ according to the ECFM-3Z model simulations and by $40 \%$ according to the Wang mechanism simulations, further reduction is required. According to the ECFM-3Z model for OP100 operating point $\mathrm{NO}_{\mathrm{x}}$ emission was reduced only slightly for $\mathrm{K}_{3}$ nozzle conicity, while no reduction was predicted by the Wang mechanism. As a conclusion, a different strategy is required in order to meet soot emission target for OP75 operating point. Furthermore, higher level of EGR need to be applied for OP100 operating point to meet the $\mathrm{NO}_{\mathrm{x}}$ target level. Increasing the EGR would result in higher soot concentration, which could also require further reduction. Therefore, in the following section application of the post-injection is studied as a possibility of further emissions reduction.

\subsection{Post-injection results}

It can be advantageous to use post-injection together with EGR to simultaneously reduce $\mathrm{NO}_{x}$ and soot with in-cylinder techniques. Reviewed studies show that post-injection strategies can be implemented without a penalty in $\mathrm{NO}_{\mathrm{x}}$ and they usually become more effective in soot reduction at higher rates of EGR. Therefore, in this subsection post-injection application is investigated together with EGR for two rail pressures (1800 bar and 1500 bar) and for two nozzle $\mathrm{K}$-factors $\left(\mathrm{K}_{0}\right.$ and $\left.\mathrm{K}_{6}\right)$.

Again, firstly results of IMEP for all investigated cases are compared (Fig. 20). Presented results were normalized in regard to corresponding validated cases $\left(\mathrm{MIO}, \mathrm{K}_{0}\right.$ nozzle conicity and 1500 bar rail pressure). For both operating points application of post-injection resulted in IMEP increase (with the same total fuel amount injected). Application of higher fuel pressure and higher nozzles conicity also resulted in IMEP increase, as in MIO cases. The ECFM-3Z model and the Wang mechanism predicted similar differences in IMEP between investigated cases.

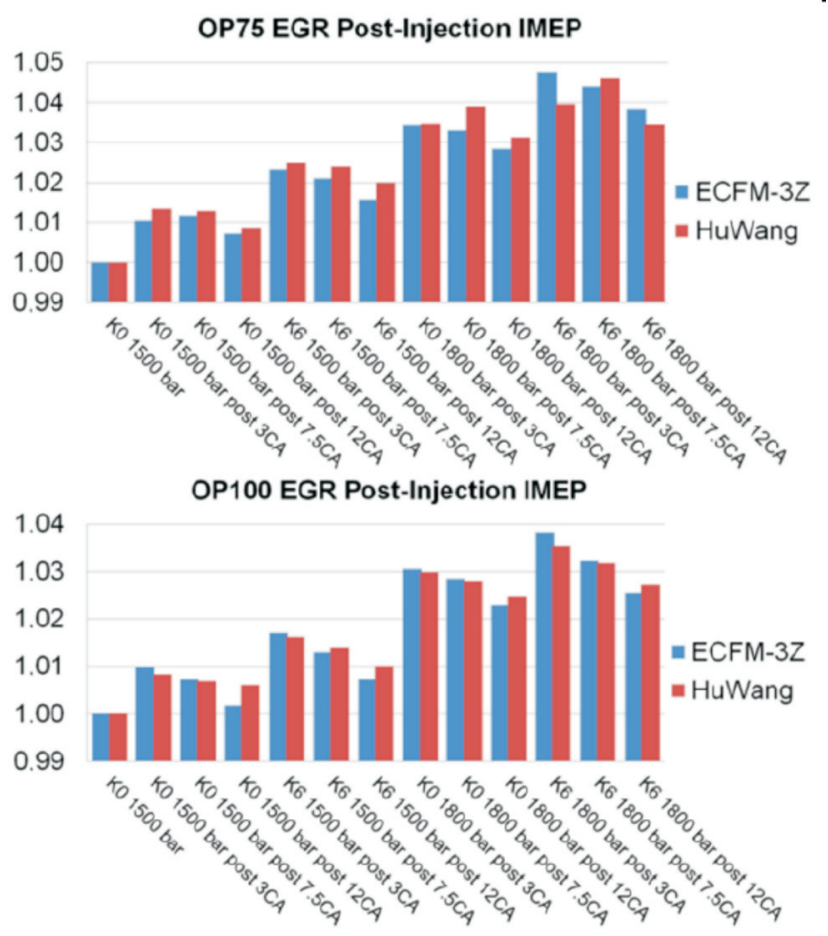

Fig. 20. Normalized IMEP for post-injection cases

Detailed 3D results of temperature, equivalence ratio and emissions formation, as well as $2 \mathrm{D}$ results of emissions 
formation are presented only for $\mathrm{K}_{0}$ nozzle and 1500 bar rail pressure in order to focus on post-injection influence on soot and $\mathrm{NO}_{x}$ concentrations. Final emissions results are presented for all cases at the end of this section as soot- $\mathrm{NO}_{x}$ trade-off graphs.

In Figures 21-24 temperatures and $\mathrm{NO}_{\mathrm{x}}$ formation at cross-section of the upper nozzle during main and postinjection are visualized for OP100 operating point with $20 \%$ of EGR. Temperatures during the main-injection were similar as in discussed MIO cases, while during the post-injection temperatures were much lower. It resulted in visibly lower $\mathrm{NO}_{\mathrm{x}}$ formation rate during the post-injection. In general similar behavior was observed for the ECFM-3Z
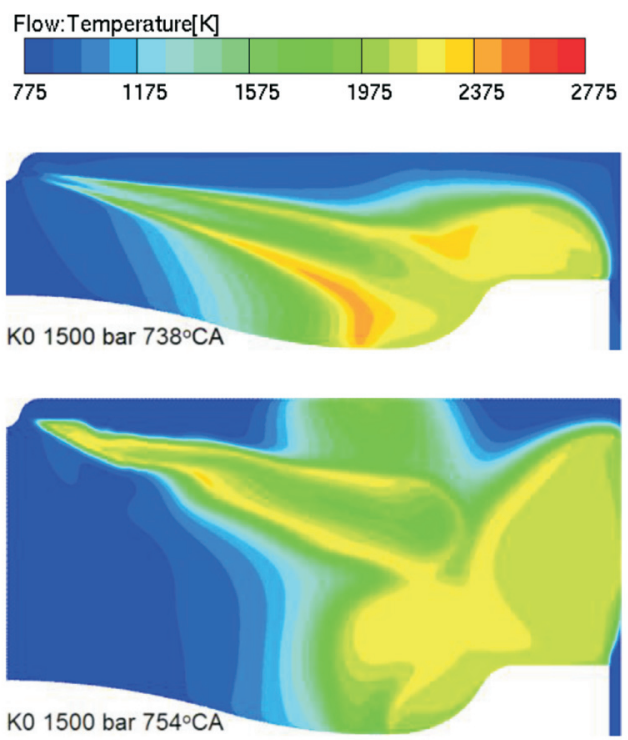

Fig. 21. 3D results of temperature predicted by the ECFM-3Z model for OP100 during main (top) and post-injection (bottom)
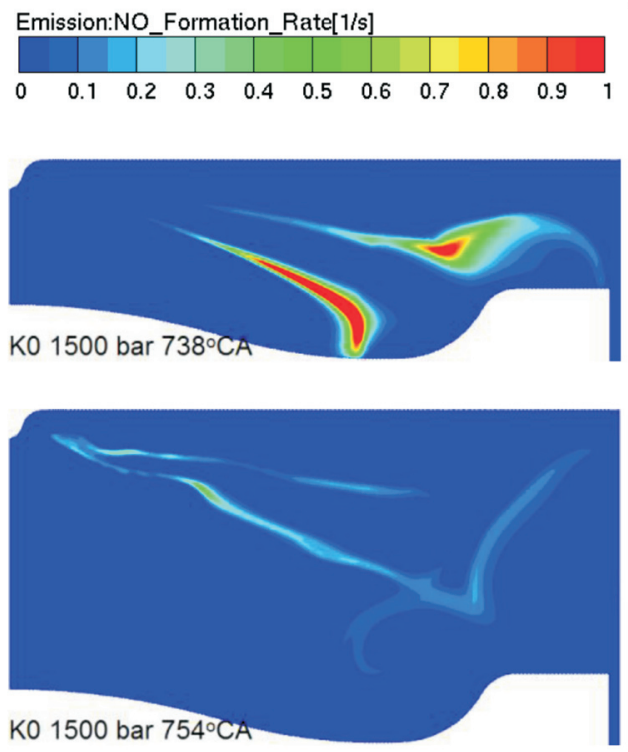

Fig. 22. 3D results of $\mathrm{NO}_{x}$ formation predicted by the ECFM-3Z model with extended Zeldovich model for OP100 during main (top) and postinjection (bottom) model and the Wang mechanism. In case of the mechanism slightly more intensive $\mathrm{NO}_{\mathrm{x}}$ formation was observed during the post-injection, what can affect overall $\mathrm{NO}_{\mathrm{x}}$ emission.
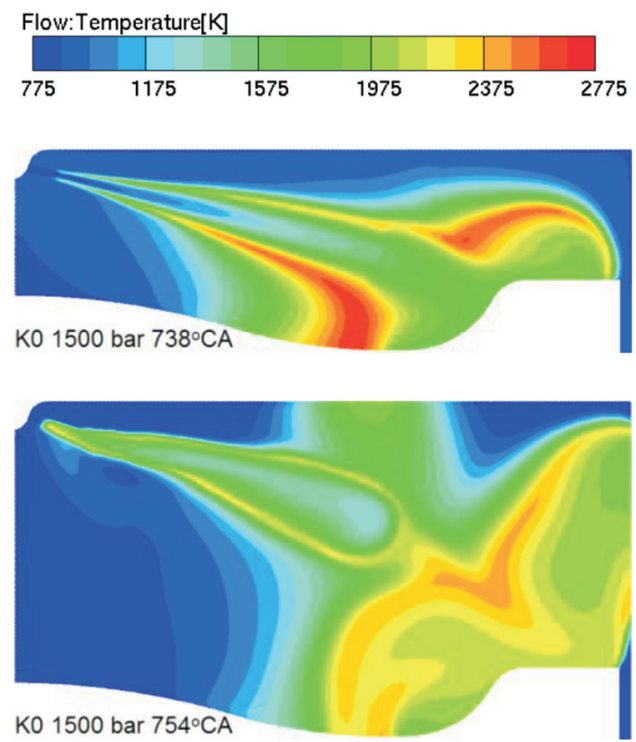

Fig. 23. 3D results of temperature predicted by the Wang mechanism for OP100 during main (top) and post-injection (bottom)
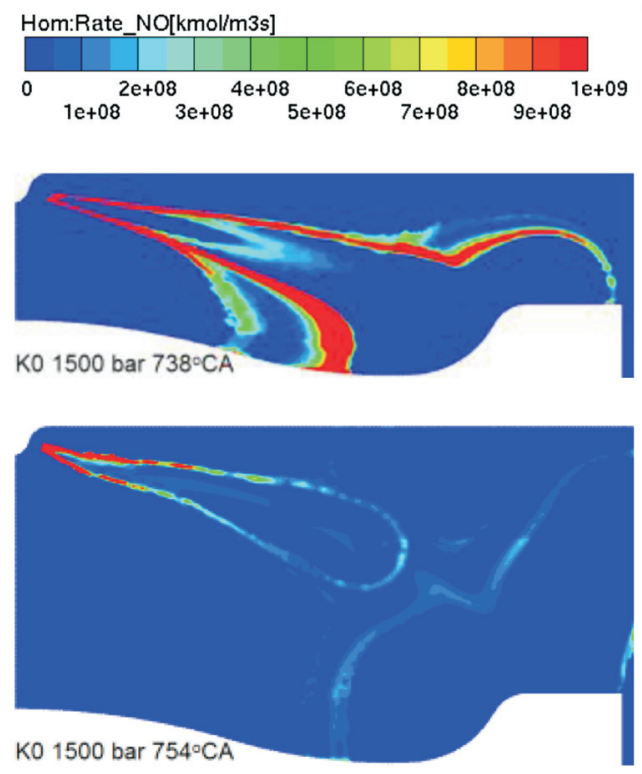

Fig. 24. 3D results of $\mathrm{NO}_{\mathrm{x}}$ formation predicted by the Wang mechanism for OP100 during main (top) and post-injection (bottom)

Post-injection $\mathrm{NO}_{\mathrm{x}}$ formation $2 \mathrm{D}$ results predicted by the extended Zeldovich model and the Wang mechanism for $\mathrm{K}_{0}$ nozzle, 1500 bar rail pressure and $20 \%$ of EGR are given in Fig. 25. According to the extended Zeldovich model the $\mathrm{NO}_{x}$ concentration for post-injection is at similar level as in the reference MIO case. In some of the cases post-injection application even reduced final $\mathrm{NO}_{\mathrm{x}}$ concentration. It is in agreement with discussed $3 \mathrm{D}$ results, where very little $\mathrm{NO}_{x}$ was formed during the post-injection and overall $\mathrm{NO}_{\mathrm{x}}$ was expected to be reduced due to shortened main-injection duration. However, results obtained with the Wang mechanism 
clearly show $\mathrm{NO}_{x}$ concentration increase with post-injection application, even though predicted temperatures do not denote it. This increase might be related to the fact that the Wang mechanism predicts $\mathrm{NO}_{\mathrm{x}}$ formation also at the flame front in regions of lower temperatures, as described in previous subsection. $\mathrm{NO}_{\mathrm{x}}$ formation in these areas is also visible during the post-injection in Fig. 24 and can increase total $\mathrm{NO}_{\mathrm{x}}$ emission.
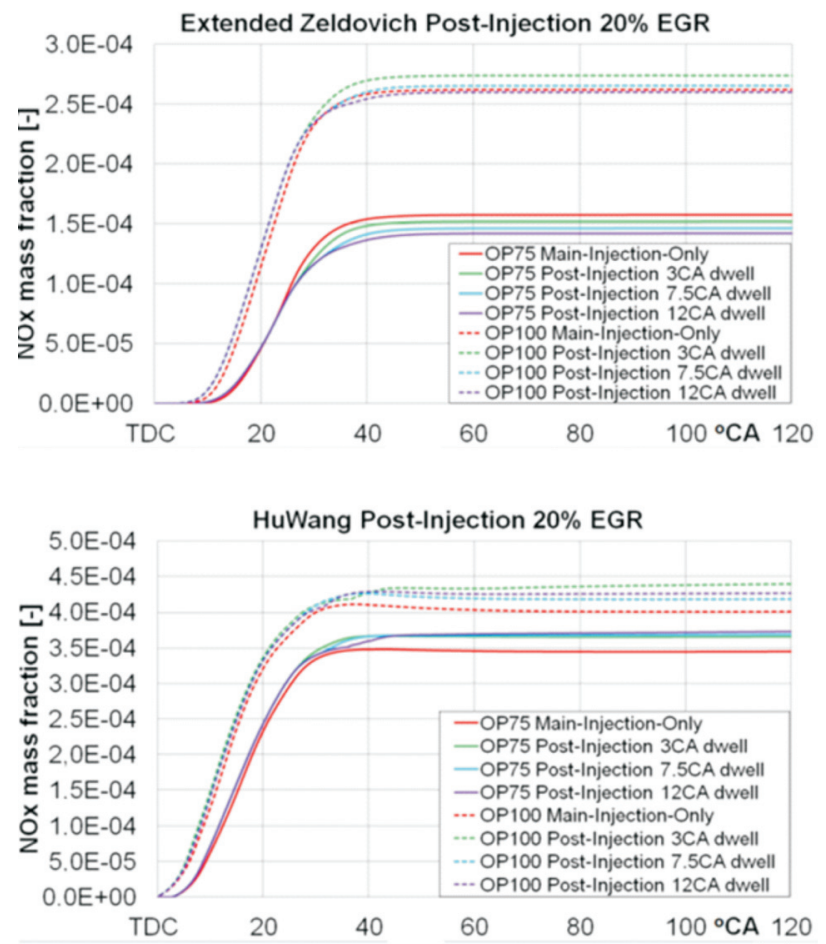

Fig. 25. $\mathrm{NO}_{\mathrm{x}}$ formation $2 \mathrm{D}$ results with post-injection for $\mathrm{K}_{0} 1500$ bar and $20 \%$ of EGR
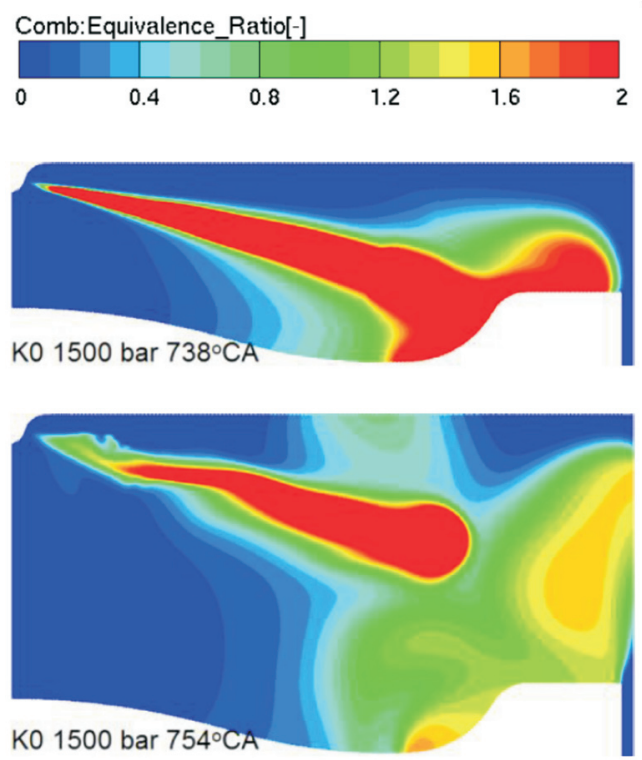

Fig. 26. 3D results of equivalence ratio predicted by the ECFM-3Z model with kinetic soot model during main (top) and post-injection (bottom)
In Figures 27-28 detailed 3D soot formation results at cross-section of upper nozzle during main and post-injection are visualized for OP100 operating point with $20 \%$ of EGR. As already described in previous subsection, most of the soot is formed in the region of equivalence ratios of $\varphi>2$ and soot oxidation area is present at the peripheries of the spray. The interdependence between the soot formation and the equivalence ratio (Fig. 26) is clearly visible for ECFM-3Z model simulations. Although the model and the mechanism predict similar soot oxidation area during the main-injection, the mechanism predicted this area to be visibly smaller during the post-injection. It can contribute to the higher soot emission concentrations in cases with post-injection predicted by the Wang mechanism.
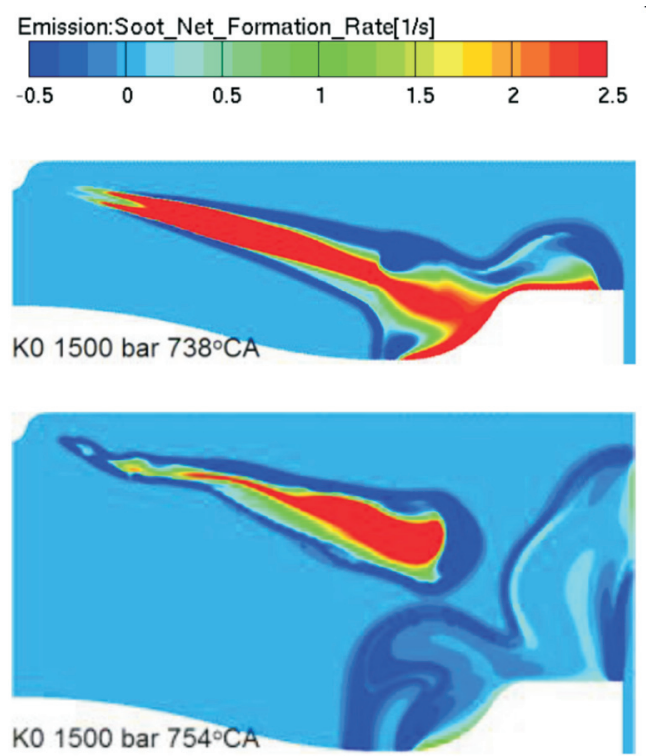

Fig. 27. 3D results of soot formation predicted by the ECFM-3Z model with kinetic soot model during main (top) and post-injection (bottom)
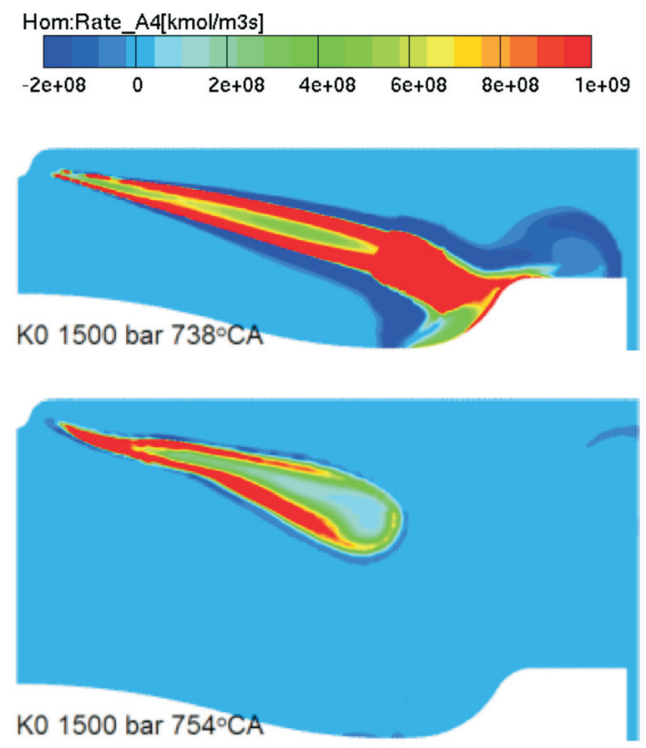

Fig. 28. 3D results of soot precursor (pyrene) formation predicted by the Wang mechanism during main (top) and post-injection (bottom) 
In Figure 29 detailed soot formation results for $\mathrm{K}_{0}$ nozzle and 1500 bar rail pressure with $20 \%$ of EGR and post-injection applied are presented. The kinetic soot model predicts that with application of the post-injection less soot is produced, mainly due to shortened main-injection. Although the soot is also produced during the post-injection, its amount is limited and final soot concentrations are significantly reduced in regard to the MIO reference cases. In case of the Wang mechanism the soot formation rate during the injection and soot oxidation rate after the injection were higher than predicted by the model. It caused the soot mass fraction to reach maximum value before the end of injection. Hence, shorter main injection does not reduce the amount of produced soot, but only cause the soot reduction process to start earlier. The post-injection takes place at the moment when most of the soot is already oxidized and for OP75 operating point resulted in small reduction of the final soot concentration in regard to the MIO reference case. As for OP100 operating point post-injection visibly increased the soot mass fraction and the final soot concentration was higher than in the MIO reference case.
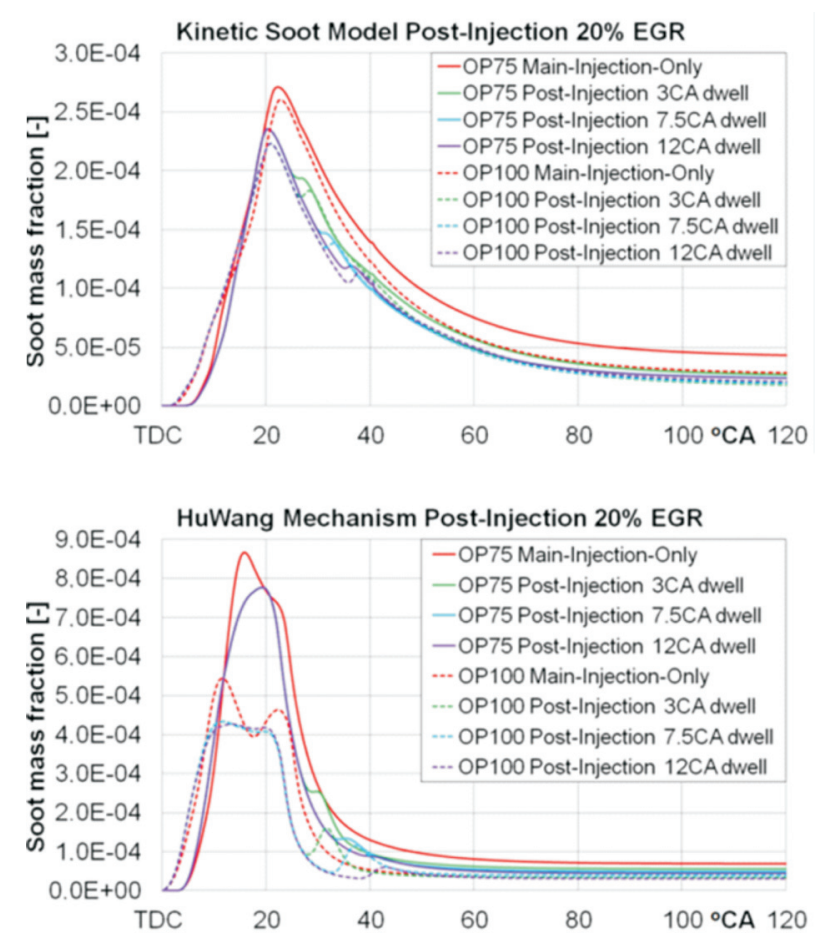

Fig. 29. Soot formation $2 \mathrm{D}$ results with post-injection for $\mathrm{K}_{0} 1500 \mathrm{bar}$ and $20 \%$ of EGR

In order to determine if application of the post-injection can contribute to the soot emission reduction and how it influences the $\mathrm{NO}_{x}$ emission, final emissions results are given in Fig. 30 as soot-NO trade-off graphs. All emissions mass fraction results were converted to $\mathrm{g} / \mathrm{kW} \cdot \mathrm{h}$ for $\mathrm{NO}_{\mathrm{x}}$ and $\mathrm{mg} / \mathrm{kW} \cdot \mathrm{h}$ for soot in order to take into account IMEP (power output) differences between cases. Then results were normalized in regard to the $\mathrm{K}_{0}$ nozzle 1500 bar MIO cases separately for OP75 operating point, OP100 operating point, the ECFM-3Z model and the Wang mechanism.
The soot- $\mathrm{NO}_{\mathrm{x}}$ trade-off for the ECFM-3Z combustion model, kinetic soot model and $\mathrm{NO}_{\mathrm{x}}$ extended Zeldovich model show that in general post-injection application caused significant soot emission reduction without a penalty in $\mathrm{NO}_{\mathrm{x}}$. In some cases $\mathrm{NO}_{\mathrm{x}}$ was even reduced with the post-injection. Only for OP100 operating point, $\mathrm{K}_{6}$ nozzle and 1800 bar rail pressure $\mathrm{NO}_{\mathrm{x}}$ emission increase is observed with post-injection
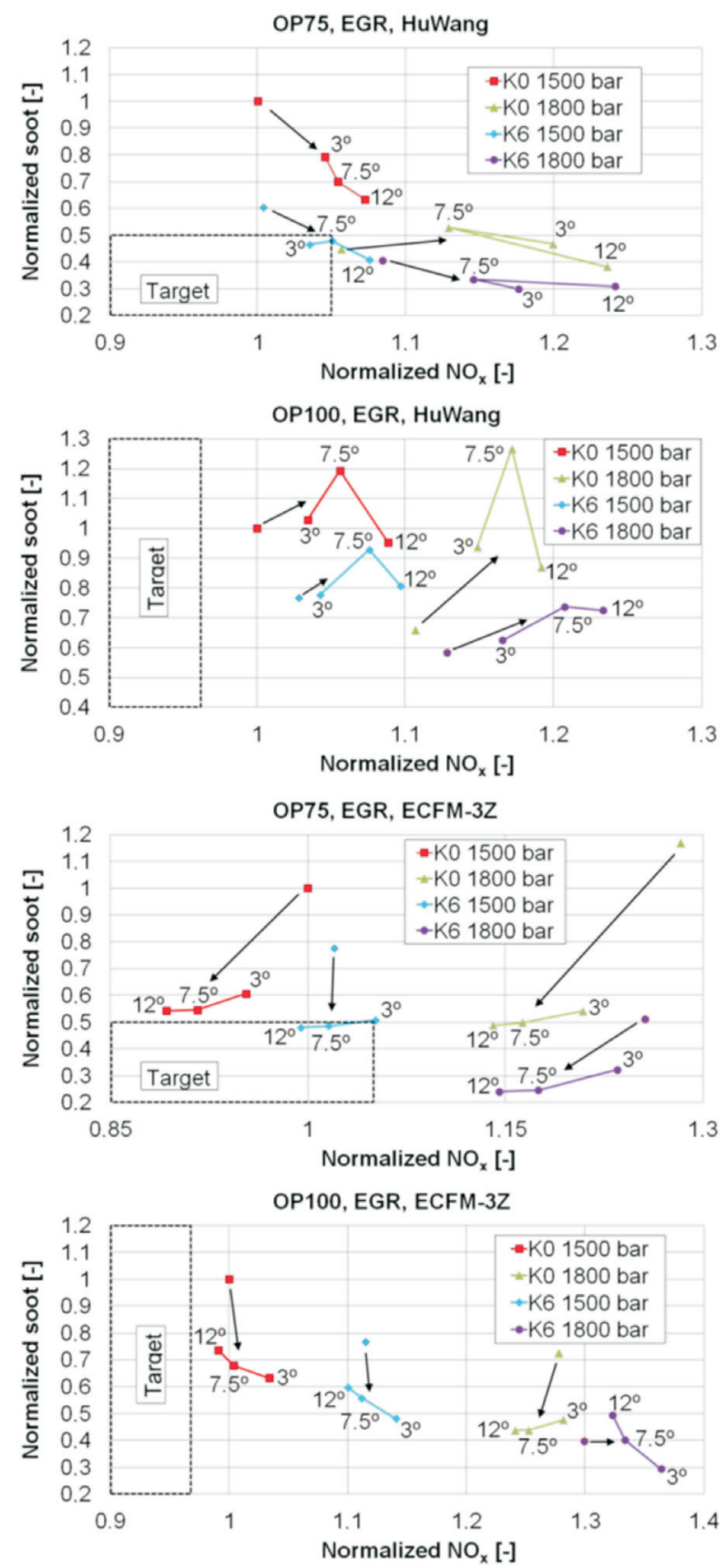

Fig. 30. Soot-NO trade-off for post-injection cases

application. For OP75 operating point longer dwell between main and post-injection caused soot and $\mathrm{NO}_{\mathrm{x}}$ concentrations reduction. Although for OP100 operating point there is no pattern for soot, the $\mathrm{NO}_{\mathrm{x}}$ was also reduced with longer dwell after the main-injection. This kind of soot- $\mathrm{NO}_{x}$ behavior was expected and allowed to meet the emissions targets for OP75 operating point. Application of the $\mathrm{K}_{6}$ nozzle conicity, 1500 
bar rail pressure and post-injection with $12{ }^{\circ} \mathrm{CA}$ and $7.5^{\circ} \mathrm{CA}$ resulted in reduction of the soot concentration by over $50 \%$ in regard to the reference case, without a penalty in $\mathrm{NO}_{\mathrm{x}}$.

As for simulations with the Wang mechanism, a meaningful soot reduction with the post-injection application was obtained only for OP75 operating point and 1500 bar rail pressure. However, it was at expense of increased $\mathrm{NO}_{\mathrm{x}}$ emission in mentioned cases. For $\mathrm{K}_{6}$ nozzle conicity application of the post-injection with $7.5^{\circ} \mathrm{CA}$ and $12^{\circ} \mathrm{CA}$ dwells after the main-injection allowed to meet emission targets. In the rest investigated cases application of the post-injection resulted in both soot and $\mathrm{NO}_{\mathrm{x}}$ emissions increase in regard to corresponding MIO cases. This behavior is not in agreement with the one that can be found in literature and suggests that the Wang mechanism does not predict emissions properly under investigated engine operating conditions with post-injection. Taking into consideration that the mechanism was validated by authors both against MIO [6] and post-injection [7] engine operating conditions with good agreement, the correctness of the numerical model used in this study for detailed chemistry combustion simulations should be revised. For example, the multi-zone approach for chemistry solver might have influence on emissions. Therefore, all cases should be recalculated with chemistry solution for each cell in order to determine if it would change results of emissions formation. However, it would be extremely time consuming due to large number of mesh elements in the model.

\section{Conclusions}

In this study 3D CFD numerical simulations of combustion were performed in order to investigate the possibilities of $\mathrm{NO}_{\mathrm{x}}$ and soot emissions reduction in heavy-duty CI engine. Firstly, inner nozzle flow simulations for geometrically different nozzles and different rail pressures were conducted. Results obtained with these simulations were used as an spray input data for diesel combustion simulations in order to reflect real conditions best. Combustion simulations in this study were performed with ECFM-3Z combustion model for diesel-D1 fuel and with a detailed oxidation mechanism for $\mathrm{n}$-heptane in order to make a comparison between these two approaches. In case of the ECFM-3Z model soot emission was predicted with the kinetic soot model and $\mathrm{NO}_{\mathrm{x}}$ with the extended Zeldovich model. Two most important loads in terms of heavy-duty CI engine operation were considered $-75 \%$ and $100 \%$. For these operating points $\mathrm{K}_{0}$ nozzle conicity and 1500 bar rail pressure cases were chosen as a reference and validated against experimental data. EGR application was investigated as a possibility of $\mathrm{NO}_{x}$ emission reduction, while higher nozzle $\mathrm{K}$-factors and higher rail pressure, as well as post-injection application were investigated as possibilities of soot emission reduction. The following observations have been done during the combustion simulations:

- Both the ECFM-3Z model and the Wang mechanism underestimate the IMEP (and the power output). However, the mechanism prediction was closer to reality. Even considering different LHV of diesel-D1 fuel and n-heptane, the mechanism still provided more reliable results. Furthermore, ignition delay times and in-cylinder peak pressures predicted by the mechanism matched the measurement better than results obtained with the model. Therefore, it can be stated that the Wang mechanism predicts combustion process under MIO engine operating conditions better than the ECFM-3Z model. When it comes to $\mathrm{NO}_{\mathrm{x}}$ emission validation for MIO conditions the mechanism also provided more reliable results, especially in cases where EGR was applied. As for soot emission the ECFM-3Z model with the kinetic soot model predicted the soot concentration with better agreement, but only for MIO cases without EGR. In case of EGR application, model as well as the mechanism significantly overestimated soot emission.

- After model validation several measures for emission reduction were investigated. Increased rail pressure in general resulted in $\mathrm{NO}_{x}$ emission increase and soot emission reduction, as predicted both by the model and the mechanism. However, the level of emissions (concentration) change was different for individual cases. As for different nozzle $\mathrm{K}$-factors, it was observed that in general both the kinetic soot model and the Wang mechanism predict soot emission to drop with $\mathrm{K}$-factor rise. In case of the $\mathrm{NO}_{x}$ emission the extended Zeldovich model predicted the lowest concentrations for $\mathrm{K}_{3}$ nozzle conicity and the highest concentrations for $\mathrm{K}_{6}$ nozzle conicity, while $\mathrm{NO}_{\mathrm{x}}$ results obtained with the Wang mechanism were higher for higher nozzles K-factor with only one exception in investigated cases and very small differences between all $\mathrm{K}$-factors for OP75 operating point and 1500 bar rail pressure.

- Post-injection application resulted in significant soot concentration reduction without a penalty in $\mathrm{NO}_{\mathrm{x}}$ emission according to the ECFM-3Z model with kinetic soot model and extended Zeldovich $\mathrm{NO}_{\mathrm{x}}$ model. As for simulations with the Wang mechanism, soot reduction with the post-injection application was obtained only for OP75 operating point and 1500 bar rail at expense of $\mathrm{NO}_{\mathrm{x}}$ emission. In the rest investigated cases application of the post-injection resulted in both soot and $\mathrm{NO}_{\mathrm{x}}$ concentrations increase. Results of emissions concentration calculated with the mechanism for post-injection cases were not in agreement with theory and literature. Considering current understanding of post-injection influence on soot and $\mathrm{NO}_{\mathrm{x}}$ formation, the ECFM-3Z model with the kinetic soot and extended Zeldovich $\mathrm{NO}_{x}$ provided more reliable results of emissions under conditions investigated in this study. However, further investigation and results validation is necessary in order to determine which method is better for emission prediction when post-injection is applied.

- Despite the differences in results, combustion and emissions models as well as the mechanism predicted that for OP75 operating point it is possible to meet soot and $\mathrm{NO}_{\mathrm{x}}$ emission targets with $\mathrm{K}_{6}$ nozzle conicity, 1500 bar rail pressure, application of the post-injection and $20 \%$ of EGR. For OP100 operating point $20 \%$ of EGR is not enough to meet the $\mathrm{NO}_{\mathrm{x}}$ emission target. Therefore, further reduction of $\mathrm{NO}_{x}$ concentration by $5 \%$ in regard to the reference case is required. However, only slight increase of EGR should be sufficient to meet the $\mathrm{NO}_{\mathrm{x}}$ target level without exceeding the soot emission target for OP100 operating point. 


\section{Nomenclature}

$\mathrm{D}_{\text {in }} \quad$ injector orifice inlet diameter

$\mathrm{D}_{\text {out }}$ injector orifice outlet diameter

$\mathrm{K}$ injector nozzle conicity factor

L injector orifice length

$\mathrm{m}_{\text {main }}$ fuel mass injected during the main-injection

$\mathrm{m}_{\text {post }}$ fuel mass injected during the post-injection

$\varphi \quad$ equivalence ratio

$\mathrm{p}_{\text {in }} \quad$ pressure at injector inlet boundary condition

$\mathrm{p}_{\text {out }} \quad$ pressure at injector outlet boundary condition

$\mathrm{r} \quad$ injector orifice inlet rounding

BDC bottom dead center

CI compression-ignition

ECFM-3Z 3-Zones Extended Coherent Flame Combustion Model

EGR exhaust gas recirculation
EPA Environmental Protection Agency

FSN filter smoke number

HRR heat release rate

IMEP indicated mean effective pressure

IMO International Maritime Organization

LCV lover calorific value

MIO main-injection-only engine operation

OP75 $75 \%$ load engine operating point

OP100 100\% load engine operating point

PAH polyaromatic hydrocarbons

PFP peak firing pressure

TDC top dead center

UHC unburned hydrocarbons

\section{Bibliography}

[1] Metz B., Davidson O.R., Bosch P.R., Dave R., Meyer L.A. Contribution of working group III to the fourth assessment report of the intergovernmental panel on climate change. Cambridge University Press, Cambridge, United Kingdom and New York 2007.

[2] Emission Standards, International Maritime Organization. [Accessed: 20.03.2015]. www.dieselnet.com/standards/inter/ imo.php\#nox.

[3] Nehmer D., Reitz R. Measurement of the effect of injection rate and split injections on diesel engine soot and $\mathrm{NO}_{\mathrm{x}}$ emissions. SAE Technical Paper 940668, 1994.

[4] Tow T., Pierpont D., Reitz R. Reducing particulates and $\mathrm{NO}_{x}$ emissions by using multiple injections in a heavy duty D.I. diesel engine. SAE Technical Paper 940897, 1994.

[5] Pierpont D., Montgomery D., Reitz R. Reducing particulate and NOx using multiple injections and EGR in a DI diesel. SAE Technical Paper 950217, 1995.

[6] O'Connor J., Musculus M. Post injections for soot reduction in diesel engines: a review of current understanding. SAE Technical Paper 2013-01-0917, 2013.

[7] You Z., Hessel R., Reitz R. CFD study of soot reduction mechanisms of post-injection in spray combustion. SAE Technical Paper 2015-01-0794, 2015.
[8] Wang H., Yao M., Reitz R. Development of a reduced primary reference fuel (PRF) mechanism for IC engine combustion simulations. Energy \& Fuels, 27 (12), 2013, 7843-7853.

[9] Wang H., Reitz D., Yao M., Yang B., Jiao Q., Qiu L. Development of an n-heptane/n-butanol/PAH mechanism and its application for combustion and soot prediction. Combustion and Flame, 160, 2013, 504-519.

[10] Hanjalić K., Popovac M., Hadziabdić M. A robust near-wall elliptic-relaxation eddy-viscosity turbulence model for CFD. International Journal of Heat and Fluid Flow, 25(6), 2004, 1047-1051.

[11] AVL Fire spray module manual v2014.

[12] AVL Fire combustion module manual v2014.

[13] AVL Fire emission module manual v2014.

[14] Afzal S. Prediction of diesel-spray preparation of a commonrail injector. Technische Universität München. Master's Thesis, 2014.

[15] Lakshminarayanan P.A., Aghav Y.V. Modelling diesel combustion. Springer, Netherlands 2010.

Pyszczek Rafał, MSc. - PhD Student at the Faculty of Power and Aeronautical Engineering at Warsaw University of Technology.

e-mail: rafal.pyszczek@itc.pw.edu.pl

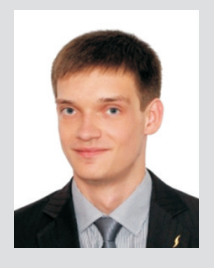

Schmalhorst Carsten, DEng. - AVL Deutschland.

e-mail: Carsten.Schmalhorst@avl.com
Prof. Teodorczyk Andrzej DSc., DEng.-- Professor at the Faculty of Power and Aeronautical Engineering at Warsaw University of Technology.

e-mail: andrzej.teodorczyk@itc.pw.edu.pl

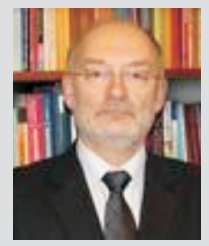

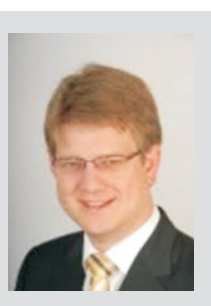

